\title{
Distribution of Gentamicin in the Guinea Pig Inner Ear after Local or Systemic Application
}

\author{
Shun-ichi Imamura ${ }^{1}$, And Joe C. Adams $^{2}$ \\ ${ }^{1}$ Department of Otolaryngology, Shinshu University School of Medicine, 3-1-1 Asahi, Matsumoto, Nagano 390-8621, Japan \\ ${ }^{2}$ Department of Otology and Laryngology, Harvard Medical School, Massachusetts Eye and Ear Infirmary, Boston, MA 02114, \\ USA
}

Received: 1 August 2001; Accepted: 12 October 2002; Online publication: 15 January 2003

\begin{abstract}
Uptake and retention of gentamicin by cells in the guinea pig inner ear after a single peritoneal injection or local application on the round window were investigated using immunocytochemistry to localize the drug. The cells that accumulated the drug under the two conditions were the same, but staining for the drug was more intense and was often accompanied by widespread cochlear degeneration following local application. Soon after drug administration by either route, there was diffuse staining for the drug throughout all tissue within the labyrinth, including bone. At later times when distinct cell staining became evident, virtually all cell types were found to be positive, with several cell types staining more darkly for the drug than hair cells, indicating that hair cells were not the most avid in accumulating gentamicin. The infracuticular portion of auditory and vestibular hair cells as well as type III fibrocytes of the spiral ligament were positively stained in almost all cases and these sites were found to be positive for as long as six months post administration. In animals with loss of the organ of Corti, there was unusually intense staining for gentamicin in root cells of the spiral ligament, in marginal cells of the stria vascularis, and in cells of the spiral limbus. Dark staining of surviving cells in cases with overt tissue destruction suggests that variability in the extent of damage caused by the drug was determined more by the degree of its local uptake than by differences in animals' capacities to
\end{abstract}

Correspondence to: Joe C. Adams - Department of Otolaryngology • Massachusetts Eye and Ear Infirmary • 243 Charles Street • Boston, MA 02114. Telephone: (617) 573-3975; fax: (617) 720-4408; email: jadams@meei.harvard.edu metabolize the drug systemically. The present results show that gentamicin may damage or destroy all cochlear cells following a single round window application. The findings broaden the scope of our knowledge of cochlear gentamicin uptake and damage and have implications for treatment of patients with vestibular disorders by infusion of aminoglycosides into the middle ear, as well as implications for prospects of rehabilitating patients that have been deafened by aminoglycosides.

Keywords: aminoglycoside, immunocytochemistry, inner ear, ototoxicity

\section{INTRODUCTION}

Interest in the ototoxic properties of aminoglycoside antibiotics has prompted repeated radioimmunoassay and biochemical studies of pharmacokinetics in inner ear fluid and tissues after chronic treatment with these drugs. Many of these studies suggested that rapid uptake, early saturation, and long exposure of the tissue to the drug may be responsible for the pronounced toxicity in the inner ear (see reviews by Federspil 1981; Hawkins and Johnsson 1981; Tran Ba Huy et al. 1981a,b, 1983, 1986; Dulon et al. 1986; Ryback 1986; Nakashima et al. 2000). For obvious reasons most previous studies have focused attention upon drug uptake and subsequent damage to sensory cells. The present work is an immunocytochemical approach to pharmacokinetics of gentamicin in the ear that broadens the scope of analysis to all cochlear cell classes and includes a single-dose paradigm in- 
volving systemic or local application and an extended time scale for the analysis of effects.

Recent clinical use of aminoglycoside drugs for treatment of vestibular disorders has renewed interest in the cellular mechanisms of aminoglycoside ototoxicity at the molecular level (Wersall 1995; Forge and Schacht 2000; Nakashima et al. 2000). Previous studies of the distribution of aminoglycoside drugs at the cellular level revealed a specific uptake and slow release of the drugs in sensory cells (Balogh et al. 1970; von Ilberg et al. 1971; Portmann et al. 1974; Tachibana et al. 1985; Hayashida et al. 1985, 1989; Hayashida 1989; DeGroot et al. 1990; Hiel et al. 1992a,b; Dulon et al. 1993; Aran et al. 1999). A multistep model of aminoglycoside toxicity has been offered to explain molecular mechanisms of the toxicity (Schacht 1986; Williams et al. 1987). An understanding of the uptake and retention of the drugs by both sensory and other cells is critical in the models of toxicity mechanisms. Like sensory cells, the integrity of nonsensory cells is essential for normal functioning of the cochlea. If nonsensory cells are affected by aminoglycosides, it is necessary to know the nature and extent of such effects in order to understand how the entire cochlea is affected by these drugs. There are indications that the state of nonsensory cells can affect the cochlea's response to aminoglycosides. For example, the spiral ligament is the primary site of cochlear pathology in guinea pigs which have had the endolymphatic duct surgically obstructed to induce endolymphatic hydrops (Ichimiya et al. 1994; Nadol et al. 1995). Following endolymphatic duct obstruction, guinea pigs are more susceptible to aminoglycoside toxicity (Kimura et al. 1991), a finding which suggests that hair cell vulnerability is influenced by the state of cells within the spiral ligament. Another indication that the state of nonsensory cells can affect susceptibility to aminoglycoside toxicity is the well-known synergistic toxic interaction of aminoglycosides and loop diuretics first described by Brummett et al. (1975). Synergistic toxic interactions of aminoglycosides and loop diuretics have been studied repeatedly, and a similar toxic synergistic action also occurs with combined kanamycin and aminooxyacetic acid (AOAA), a drug that, like loop diuretics, reduces the endolymphatic potential (Bryant et al. 1984). Curiously, acute effects of locally applied gentamicin upon cochlear microphonic potentials are prevented if the gentamicin is administered during the period of endolymphatic potential suppression induced by furosemide or AOAA (Takada et al. 1985), which indicates that suppression of endolymphatic potential per se is not essential for the toxic synergisms. Nevertheless, the marked effects of loop diuretics and AOAA upon the endolymphatic potential indicate that these drugs affect mainly

\begin{tabular}{|c|c|c|c|}
\hline \multicolumn{4}{|c|}{ TABLE 1} \\
\hline \multicolumn{4}{|c|}{ Treatments } \\
\hline \multirow[b]{2}{*}{$\begin{array}{l}\text { Survival } \\
\text { periods }\end{array}$} & \multirow[b]{2}{*}{$\begin{array}{l}\text { Systemic } \\
\text { injection }\end{array}$} & \multicolumn{2}{|c|}{ Round window } \\
\hline & & $\begin{array}{l}\text { Commercial } \\
\text { solution }\end{array}$ & $\begin{array}{c}\text { Artificial solution } \\
\text { perilymph }\end{array}$ \\
\hline $30 \mathrm{~min}$ & 2 & & \\
\hline $1 \mathrm{~h}$ & 2 & & \\
\hline $2 \mathrm{~h}$ & 2 & & \\
\hline $6 \mathrm{~h}$ & 2 & 1 & \\
\hline $12 \mathrm{~h}$ & 2 & 1 & \\
\hline $24 \mathrm{~h}$ & 2 & 1 & \\
\hline 4 days & 2 & 1 & 2 \\
\hline 7 days & 3 & 2 & 3 \\
\hline 1 month & 3 & 2 & 3 \\
\hline 3 months & 2 & 1 & 3 \\
\hline 6 months & 2 & 1 & 3 \\
\hline Total & 24 & 11 & 14 \\
\hline
\end{tabular}

nonsensory cells and suggest that some nonsensory cell effects may contribute to enhancement of toxic actions of aminoglycosides upon hair cells. Clearly a more comprehensive understanding of aminoglycoside uptake and toxicity within the cochlea is needed. The present report concerns uptake and retention of the drug by cells throughout the labyrinth, as well as degeneration that can be produced by local application. An accompanying article reports effects of the locally applied drug upon cytochemical profiles of surviving cells in the same animals utilized in the present report.

\section{MATERIALS AND METHODS}

\section{Animal treatment}

Fifty albino guinea pigs (weighing 250-450 g) with normal Preyer reflexes were used in this study (Table $1)$. One group of animals $(n=24)$ was given a single intraperitoneal injection (100 mg/kg IP) of commercial gentamicin solution (SoloPak Laboratories Inc., Elk Grove Village, IL; $40 \mathrm{mg} / \mathrm{ml}$ ). Twenty-five animals received a local application of gentamicin. Under pentobarbital anesthesia $(30 \mathrm{mg} / \mathrm{kg})$, the round window of the right ear was exposed using a retroauricular approach. A $50 \mu \mathrm{l}$ drop of commercial gentamicin solution was put on the round window membrane of 11 animals. Because the commercial solution frequently resulted in overt degeneration of tissues of interest, in 14 additional animals a $50 \mu \mathrm{l}$ drop of gentamicin solution, made by dissolving gentamicin powder $(40 \mathrm{mg} / \mathrm{ml}$, Sigma Chemical Co., St. Louis, MO) in artificial perilymph solution (glucose $5.5 \mathrm{mM}$, NaCl $120 \mathrm{mM}$, KCl $1.5 \mathrm{mM}$, and HEPES buffer $20 \mathrm{mM}$, pH adjusted to 7.3 with $\mathrm{NaOH}$ ), was applied to the round window. One animal received 
only the vehicle used for the commercial gentamicin solution $(3.2 \mathrm{mg} / \mathrm{ml}$ sodium bisulfite, $0.1 \mathrm{mg} / \mathrm{ml}$ edetate disodium, $1.8 \mathrm{mg} / \mathrm{ml}$ methylparaben, and 0.2 $\mathrm{mg} / \mathrm{ml}$ propylparaben, $\mathrm{pH}$ adjusted to 4.2 with $\mathrm{NaOH})$.

\section{Tissue preparation}

Treated animals were examined histologically at various survival intervals after drug administration as shown in Table 1. At the designated survival times the animals were deeply anesthetized with urethane (1.5 $\mathrm{g} / \mathrm{kg}$ ) and were exsanguinated by transcardial perfusion with $200 \mathrm{ml}$ warm physiological saline containing $0.1 \%$ sodium nitrite, followed by $200 \mathrm{ml}$ of fixative. The fixative was $10 \%$ formalin in saline containing $0.5 \%$ zinc dichromate with the $\mathrm{pH}$ adjusted to 5.0 with $\mathrm{NaOH}$ just prior to use (Mugnaini and Dahl 1983). Each bulla was opened rapidly, the stapes removed, the round window membrane perforated, and the cochlear scalae perfused with $1 \mathrm{ml}$ of fixative. The specimens were fixed for $2 \mathrm{~h}$ at room temperature. This protocol results in minimally fixed tissue, the poor state of which is evident in the micrographs. Minimal fixation was intentionally chosen so as to maximize the number of antibodies that could be utilized in the companion article, which reports changes in cytochemistry of the inner ear tissue that were produced by gentamicin administration. The fixed inner ears were immersed in $0.12 \mathrm{M}$ EDTA and stirred gently for approximately 3 weeks. The decalcified specimens were dehydrated in ethanol, cleared in xylene, and embedded in paraffin. Serial $6 \mu \mathrm{m}$ sections were cut from each paraffin block and mounted on glass slides. Every 20th section was stained with hematoxylin and eosin (H\&E).

\section{Immunohistochemical staining procedures}

Deparaffinized sections were immunostained with the biotin-amplified ABC method (Adams 1992; Imamura and Adams 1996). A monoclonal antibody against gentamicin (Fitzgerald Industries International Inc., Chelmsford, MA) was used. Sections were exposed to a $5 \%$ solution of normal horse serum (NHS) in phosphate-buffered saline (PBS, $\mathrm{pH} 7.3$ ) for $1 \mathrm{~h}$ to preabsorb sites of nonspecific antibody binding, and then were incubated for $12 \mathrm{~h}$ at room temperature with primary antisera diluted with $1 \%$ NHS-PBS. A dilution of 1:40,000 was normally used, but extremes of signal strength in individual cases necessitated adjusting the dilution from 1:1000 to $1: 2,000,000$. Following the primary antibody, sections were rinsed with PBS and incubated in $0.1 \%$ glutaraldehyde for 5 min to reduce background staining. All sections were rinsed in PBS and covered with biotinylated donkey antimouse IgG (1:200, Jackson Immunoresearch Laboratories, West Grove, PA) in 1\% NHS-PBS for 1 $\mathrm{h}$, rinsed in PBS, and incubated with Vectastain ABC reagent (Vector Laboratories, Burlingame, CA) for 1 $\mathrm{h}$. Then sections were rinsed in PBS and incubated in biotinylated tyramine (BT) solution together with $0.01 \% \mathrm{H}_{2} \mathrm{O}_{2}$ for $10 \mathrm{~min}$. The BT was made according to the previous report (Adams 1992) and diluted 1:100 with PBS just prior to use. Then sections were rinsed with $\mathrm{PBS}$ and incubated with $\mathrm{ABC}$ for $30 \mathrm{~min}$. Sites of bound primary antibodies were visualized by development for $2 \mathrm{~min}$ in $0.05 \% 3,3^{\prime}$-diaminobenzidine- $0.01 \% \mathrm{H}_{2} \mathrm{O}_{2}$ substrate medium in $0.1 \mathrm{M}$ phosphate buffer. Control procedures included omission of primary antiserum from the staining sequence and limiting dilutions of primary antisera. Positive controls were obtained on sections from kidney of animals that received a systemic gentamicin injection. In the local treatment cases, the nontreated ear, which was processed simultaneously with the treated ear, served as a control. All reported results were verified by repeated staining of nearby sections. Microscopy was performed with a Zeiss Universal microscope. Images of the results were acquired with a digital camera using Image 1 and Metamorph (Universal Imaging, West Chester, PA). Most tissue sections were used to study cytochemical consequences of gentamicin uptake by specific cell classes. Results of those investigations are reported in the companion article.

The care and use of the animals reported on in this study were approved by the Animal Care and Use Committee of the Massachusetts Eye and Ear Infirmary.

\section{RESULTS}

Control ears, those which received the vehicle only and the nontreated ears of the local administration cases, showed no immunoreaction. Just as in previous studies of hair cell loss following chronic, systemic administration of aminoglycosides, in the present study there was considerable variability between animals in the apparent amount of gentamicin accumulation and in the extent of cytopathology. Soon after treatment of both locally and systemically treated animals, all labyrinthine tissue was immunostained for gentamicin. Initially there was a diffuse, pervasive staining throughout the cochlea, including the bone. At short survival times, staining with very high dilutions of anti-gentamicin showed the highest concentrations of antigen were in perivascular spaces of bone and in submucosal tissue of the middle ear. As the pervasive staining diminished, a variety of individual cell types within the cochlea were found to be gentamicin positive. The degree of staining varied 
TABLE 2

Distribution of gentamicin after systemic injection ${ }^{\mathrm{a}}$

Survival periods

\begin{tabular}{|c|c|c|c|c|c|c|}
\hline \multirow[b]{2}{*}{ Sites of staining } & \multicolumn{6}{|c|}{ Survival periods } \\
\hline & $1 / 2-2 h$ & $6 h$ & $12 h$ & $24 h$ & 4, 7 days & 1-6 months \\
\hline \multicolumn{7}{|l|}{ Cochlea } \\
\hline Outer hair cells & + & ++ & ++ & ++ & ++ & + \\
\hline Inner hair cells & \pm & \pm & \pm & \pm & 0 & 0 \\
\hline Deiters' cells & ++ & \pm & \pm & \pm & \pm & \pm \\
\hline Cells beneath basilar membrane & + & ++ & ++ & ++ & + & $+\sim 0$ \\
\hline \multicolumn{7}{|l|}{ Spiral ligament } \\
\hline Type I fibrocytes & ++ & + & + & \pm & \pm & 0 \\
\hline Type II & + & ++ & ++ & ++ & + & $\pm \sim 0$ \\
\hline Type III & \pm & \pm & ++ & ++ & ++ & $+\sim \pm$ \\
\hline Root cells & \pm & \pm & + & + & $\pm \sim+$ & 0 \\
\hline Stria vascularis basal and intermediate & $\pm \sim+$ & + & + & + & 0 & 0 \\
\hline Spiral limbus & diffuse & ++ & $\begin{array}{l}++ \\
\text { fibrocytes }\end{array}$ & + & \pm & $\pm \sim 0$ \\
\hline Nerve fibers & ++ & + & + & + & \pm & \pm \\
\hline Spiral ganglion & $0 \sim+$ & $\pm \sim+$ & $\pm \sim+$ & \pm & \pm & 0 \\
\hline \multicolumn{7}{|l|}{ Vestibular system } \\
\hline Hair cells & 0 & $\begin{array}{l}0 \sim+ \\
\text { subcuticular }\end{array}$ & ++ & ++ & ++ & + \\
\hline Connective tissue & ++ & ++ & ++ & + & \pm & 0 \\
\hline Nerve fibers & ++ & + & + & + & + & $\pm \sim 0$ \\
\hline Vestibular ganglion & $0 \sim \pm$ & $0 \sim \pm$ & $0 \sim \pm$ & $0 \sim \pm$ & \pm & \pm \\
\hline
\end{tabular}

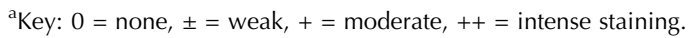

markedly between cell types, as did the time course of their staining. Details concerning various cells' uptake and retention of the drug are presented according to their locations within the labyrinth. Results are summarized in Table 2. A diagram summarizing uptake and retention of the antigen by different cell types is shown in Figure 7.

\section{Systemic administration}

Both inner ears of all animals receiving systemic treatment showed very similar immunostaining patterns. Staining patterns of animals with the same survival times were similar, but there were considerable differences in staining intensities of given sites between animals. No obvious degeneration of any cell type was present in the H\&E material.

\section{Organ of Corti}

At $2 \mathrm{~h}$ post administration, staining of OHCs and Deiters' cells was readily apparent (Fig. 1A). Staining was present throughout the cytoplasm, and in OHCs there was a reticular pattern to the staining (as illustrated for $6 \mathrm{~h}$ survival in Fig. 2A). In some cases Deiters' cells were more darkly stained than OHCs (Fig. 1A). Pillar cells, Claudius cells, and IHCs were also sometimes faintly stained (not illustrated).

The staining intensity of OHCs reached its maximum at approximately $6 \mathrm{~h}$ post administration. Ini- tially there was staining of OHCs in all cochlea turns. The pattern of staining of OHCs changed with increasing survival times. At $6-12 \mathrm{~h}$ survival times the pattern of the reaction product was reticular and present throughout the cytoplasm (Figs. IB, 2A). At $24 \mathrm{~h}$ survival within the cells of the basal turn there was darker staining at the apex of OHCs. The stained region was immediately beneath the cuticular plate (inset in Fig. 2B and 2D filled arrowhead). At 4 days survival there was a prevalence of staining of the infracuticular region of OHCs in all cochlear turns. At longer survival times only the apical staining remained in the OHCs (Fig. 1B-F). No consistent gradients in staining of OHCs were seen in the radial direction. Staining of OHCs was present in both animals with 6 month survival times.

\section{Basilar membrane}

Mesenchymal cells beneath the basilar membrane (Fig. 1B, arrowheads) were immunoreactive as early as $2 \mathrm{~h}$ post administration. This staining became weaker with increasing survival times and was not present at 6 months survival. Occasionally other mesenchymal cells lining the scala tympani and scala vestibuli were also stained (not illustrated).

\section{Lateral wall}

The spiral ligament and stria vascularis were faintly and diffusely stained at $30 \mathrm{~min}$ post injection. This 


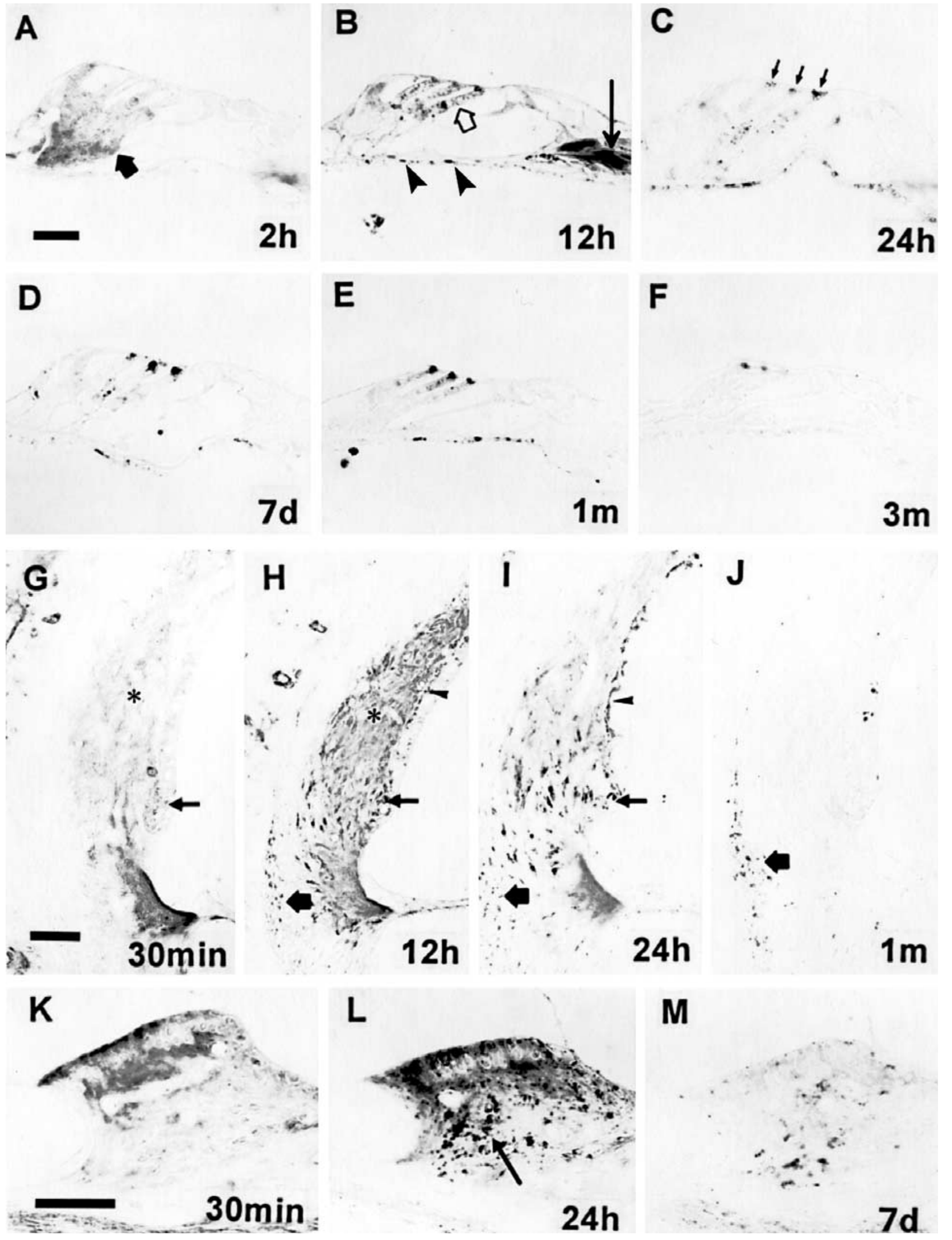


pattern was replaced by one that showed moderate staining of strial basal cells beginning at $6 \mathrm{~h}$ post administration (not illustrated). Strial basal cells were stained in all turns of the cochlea. Staining of strial basal cells became more conspicuous as diffuse staining of the spiral ligament diminished with increasing survival times (arrowheads in Figs. 1H, 1I, and $2 \mathrm{~B}$ ). At $6 \mathrm{~h}$ post injection the spiral ligament, but not the stria vascularis, was clearly stained (not shown). At $12 \mathrm{~h}$ the contrast in staining differences between these two spaces was more striking (Fig. 1H). At $12 \mathrm{~h}$ type I fibrocytes were diffusely stained and were clearly darker than the surrounding spiral ligament $(1 \mathrm{H}$, region of the asterisk). Most cells within the spiral ligament, including type I fibrocytes, external sulcus cells, and root cells, were also diffusely stained. In contrast, strial marginal cells and strial intermediate cells were not stained, suggesting that the strial vasculature is less permeable to gentamicin than extrastrial vasculature. Unlike other cochlear cells, type I fibrocytes, which can be identified by their characteristic proximity to the basal portion of the stria vascularis (region of the asterisk in Figs. 1G, $1 \mathrm{H}$, and $2 \mathrm{~B}$ ), never showed punctate staining but only diffuse staining. Little staining of type I fibrocytes was present beyond $24 \mathrm{~h}$ post administration.

In the region adjacent to the spiral prominence, type II fibrocytes surround the root processes, which extend from the external sulcus into the spiral ligament. Cells within the root processes have abundant cytoplasm and, even when they are unstained, can be distinguished from type II fibrocytes because the latter have small somata and little cytoplasm. Type II fibrocytes and root cells were stained as early as $30 \mathrm{~min}$ post administration (Fig. 1G). Staining of the type II cells was dispersed and granular. These cells stained more darkly that type I fibrocytes (Figs. 1G-I and 2B) and more darkly than the organ of Corti (Fig. 2B). In some instances they were found to be immunoreactive for as long as 1 month post administration (not shown). A small group of cells situated apical to the stria vascularis that morphologically and cytochemically resemble type II fibrocytes, suprastrial cells (Schulte and Adams 1989; Kikuchi et al. 1995), showed the same time course of staining for gentamicin as the type II fibrocytes situated in the region of the spiral prominence (not illustrated).

Type III fibrocytes are located within the spiral ligament adjacent to the bone in the basal portion of each cochlear turn (large arrows in Figs. 1H-J and 2B). In the basal turn, there are two varieties of type III fibrocytes: those with abundant cytoplasm and those with little cytoplasm. Both varieties were positive for gentamicin in the basal turn. In more apical turns there was no evidence of immunostaining of the type III fibrocytes with abundant cytoplasm. Type III fibrocytes stained positively for gentamicin were apparent as soon as the diffuse staining of the spiral ligament was eliminated. Their staining intensity reached a maximum at about $12 \mathrm{~h}$ post administration (Fig. 1H, thick arrow). Dense staining of these cells remained for as long as 7 days. Reduced numbers of stained type III fibrocytes were present at 1 month survival (Fig. 1J), but some were stained at 6 month survival times.

\section{Spiral limbus}

At 30 min post administration there was diffuse staining within the spiral limbus in all cochlear turns. The surface of spiral limbus facing the endolymphatic space was darkly stained at this time. This surface staining was largely eliminated by $24 \mathrm{~h}$ post administration. The apical portion of interdental cells, near the scala media, was also stained (Fig. 1K,L). As the diffuse extracellular staining gradually decreased, beginning around $12 \mathrm{~h}$ post administration, fibro-
FIG. 1. Immunostaining for gentamicin of the cochlea following systemic application. Numbers on the photos indicate survival periods. A. Deiters' cells (filled arrow) are immunoreactive for gentamicin. B. Immunostaining for gentamicin in the cytosol of outer hair cells (OHCs) shows a reticular pattern (open arrow). The arrow indicates stained radial fibers. C-F. The subcuticular plate region of OHCs (arrows in $\mathbf{C}$ ) shows spotty reaction product for gentamicin. G-J. Immunostaining for gentamicin in the lateral wall of the cochlea shows different patterns depending upon survival periods. The four images are the same view of the cochlea represented at different survival times. In $\mathbf{G}$, there is faint, indistinct immunostaining for gentamicin in the spiral ligament and stria vascularis with no clearly delineated immunoreactive cells. (To compare this staining within background levels, compare with J.) In $\mathbf{H}$, type I (asterisk), type II (small arrow), and type III fibrocytes (large arrow) of the spiral ligament are positive for gentamicin. Basal cells (arrowhead) of the stria vascularis are positive. In I, type II fibrocytes and root cells (small arrow) and type III fibrocytes (large arrow) of the spiral ligament are immunoreactive for gentamicin. Basal cells (arrowhead) of the stria vascularis are also positive. In J, only type III fibrocytes (large arrow) of the spiral ligament are positive for gentamicin. The reaction product in the stria vascularis is an artifact produced by the enzymatic activity of erythrocytes. K-M. Immunostaining for gentamicin of the spiral limbus shows diverse patterns depending upon survival periods. In $\mathbf{K}$, there is diffuse immunostaining for gentamicin in the spiral limbus. In $\mathbf{L}$, fibrocytes (arrow) of the spiral limbus are positive for gentamicin and there is diffuse staining in the upper surface of the limbus. In $\mathbf{M}$, only fibrocytes of the spiral limbus are positive for gentamicin. $\mathbf{E}$ and $\mathbf{F}$ are from basal turn, others are from second turn of the cochlea. The scale bar in $\mathbf{A}=20 \mu \mathrm{m}$ and applies to the $\mathbf{B}-\mathbf{F}$. The scale bar in $\mathbf{G}=50 \mu \mathrm{m}$ and applies to the $\mathbf{G}-\mathbf{J}$. The calibration bar in $\mathbf{K}=50 \mu \mathrm{m}$ and applies to the $\mathbf{K}-\mathbf{M}$. 

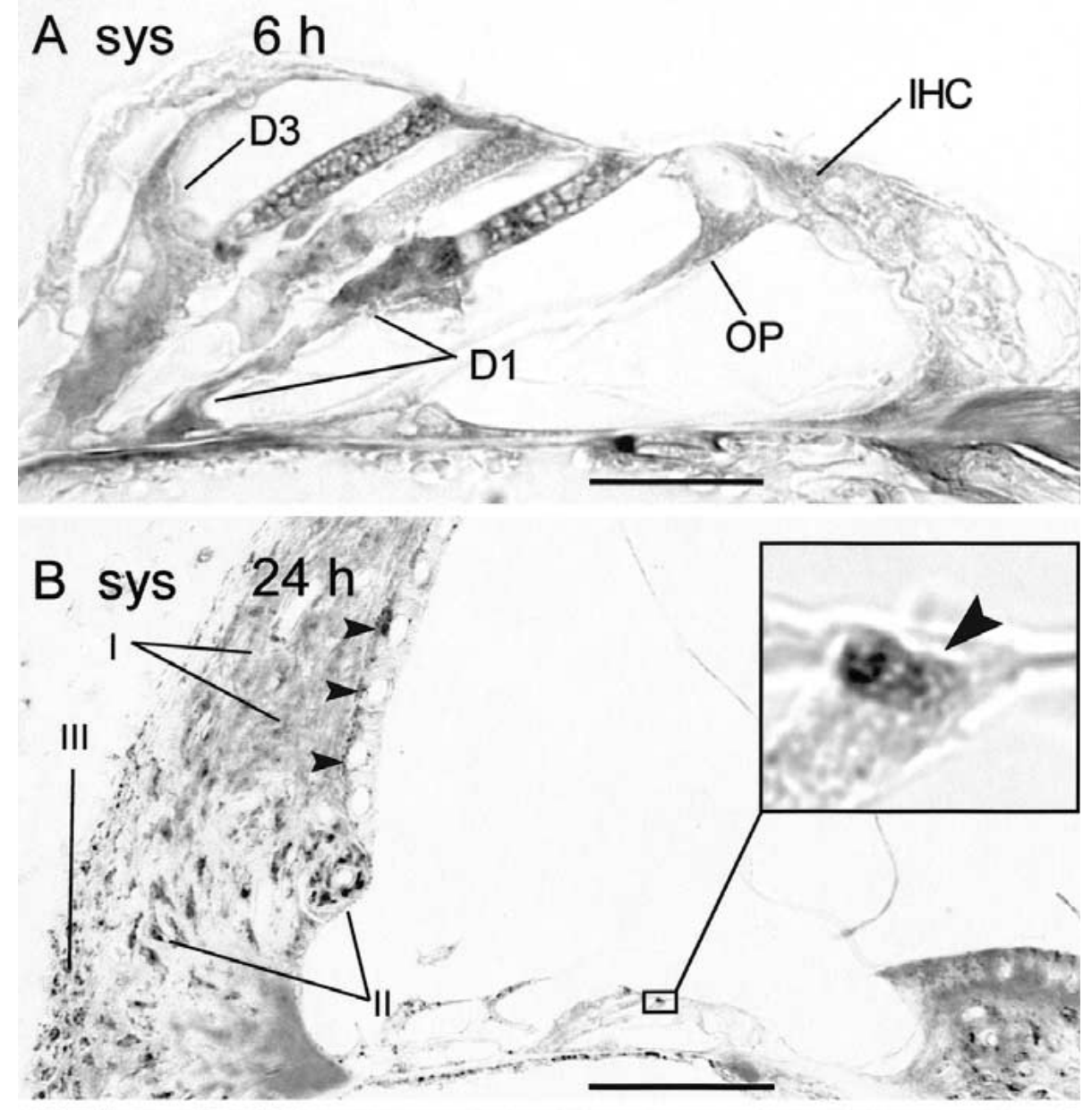

\section{C local $4 \mathrm{~h}$}
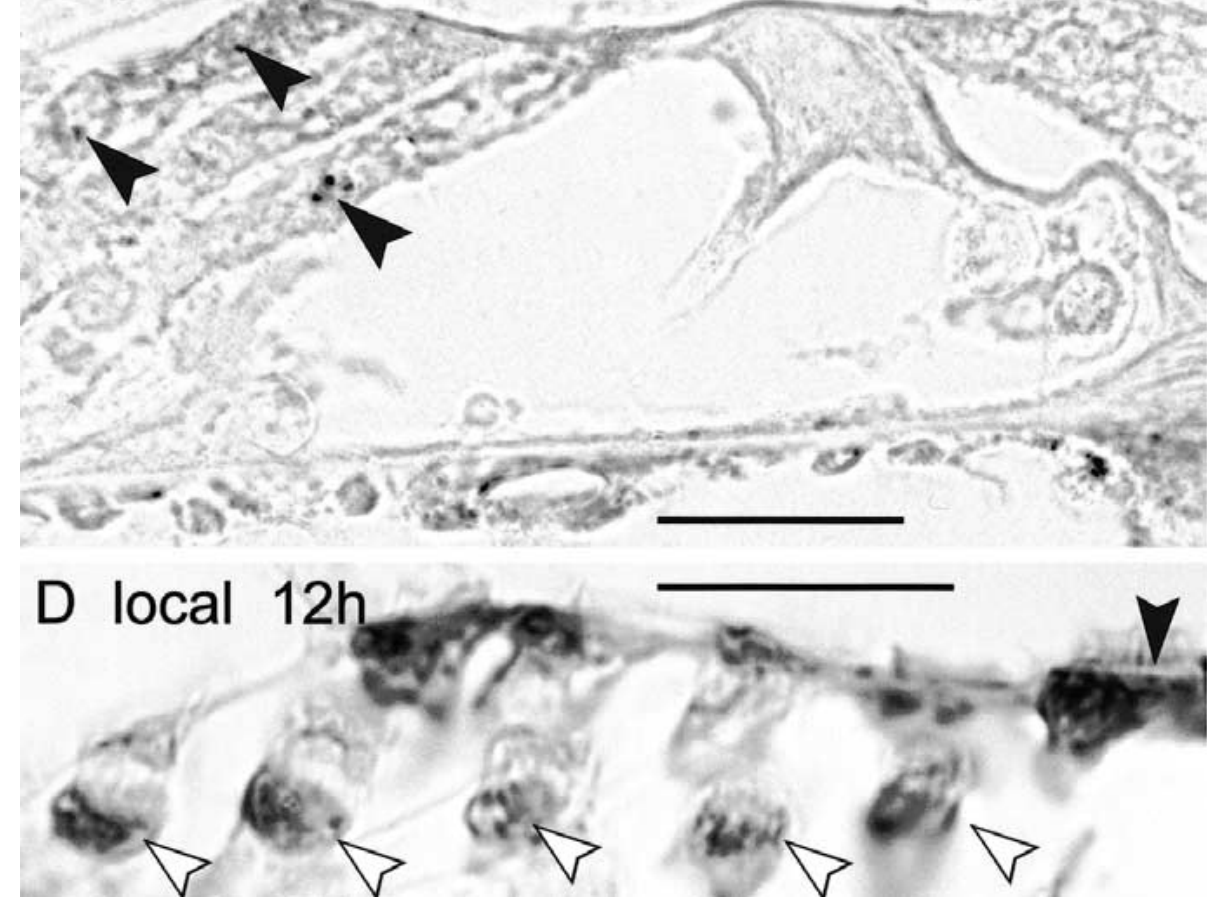
cytes within the limbus were darkly stained (Fig. 1L). This staining remained for as long as 3 months, with increasingly fewer positive fibrocytes being present with increasing survival times.

\section{Spiral ganglion cells}

The myelinated portions of auditory nerve fibers (Fig. $1 \mathrm{~B}$, long arrow) were stained beginning $1 \mathrm{~h}$ post administration. This staining became gradually weaker but persisted for as long as 3 months. There was weak, punctate staining of spiral ganglion cells at survival times as long as one week (not illustrated).

\section{Vestibular system}

There was diffuse staining within the subepithelial connective tissue of all vestibular sense organs at 30 min post administration (asterisks in Fig. 3A,D,G). Fibrocytes within these regions were also diffusely stained. Within the maculae and ampullae this diffuse staining was largely eliminated at $24 \mathrm{~h}$ (asterisks in Fig. 3E,H). Like type I fibrocytes in the cochlea, fibrocytes associated with vestibular organs never showed punctate staining for gentamicin. There was faint staining of the vestibular nerve fibers at $30 \mathrm{~min}$ post administration (arrows in Fig. 3D,G), but this became very weak at $6 \mathrm{~h}$ survival. Vestibular hair cells never showed punctate cytoplasmic staining like that of cochlear hair cells at short survival times, but the apical portions of vestibular hair cells were stained. Staining of hair cells progressed, beginning with those of saccule, which was first apparent at $6 \mathrm{~h}$ post administration, to those of the utricle and ampullae, which were stained at $12 \mathrm{~h}$ (arrows in Fig. 3B,E,H). Staining of the apical portion of hair cells was present as long as 6 months post administration. Staining of vestibular ganglion cells was weak and inconsistent between animals but, in an extreme case, was present as long as 3 months post administration.

\section{Local application}

\section{Cellular degeneration}

In contrast to results following systemic administration, following local application of gentamicin the H\&E-stained sections showed that there was often obvious degeneration of the organ of Corti, the spiral ligament, the spiral limbus, and spiral ganglion cells. Initial experiments were done with the gentamicin for injection formulation. With this formulation there were cases with degeneration so severe that there were few surviving cell classes remaining to analyze. For this reason the formulation of the drug was changed. In cases employing the drug dissolved in artificial perilymph, there was greater variability in severity of the pathology observed following drug administration. In some of these cases there was widespread disruption of cochlear structures (the most severe is shown in Fig. 4E), but in four cases (survival times of 1 week, 1 month, 3 months, and 6 months) there was no cell loss apparent in $\mathrm{H} \& \mathrm{E}$ sections. In contrast, all cases with the gentamicin for injection formulation and survival times of 4 days or greater showed overt cochlear pathology. In keeping with previous studies, OHCs were obviously vulnerable to gentamicin toxicity, but this vulnerability was equal to or closely matched by that of Deiters' cells. Usually degeneration of the organ of Corti was most severe in the lower basal turn, with less severe effects extending apically for variable distances. Cases with the least degeneration had missing OHCs and Deiters' cells (Fig. 4B). In such cases the height of the organ of Corti was also reduced, indicating that pillar cells, although still present, were structurally abnormal (Fig. 4B). In some cases with missing OHCs, some Deiters' cells survived but were dysmorphic and their nuclei were near the basilar membrane (Fig. 4B,G).

In several cases with minimal cell loss in the organ of Corti, there was mild endolymphatic hydrops (Fig. 4C), which indicated that nonsensory cells had been affected by the drug treatment. In the case illustrated in Figure 4C, hydrops was perhaps some cell loss in
FIG. 2. Patterns of hair cell immunostaining in organ of Corti. A. Systemic injection case showing a reticular pattern of staining in $\mathrm{OHCs}$ and diffuse staining of IHC and first and third row Deiters' cells (D1, D3). Outer pillar cells (OP) and mesenchymal cells of the basilar membrane are also stained. Scale bar $=25 \mu \mathrm{m}$. B. Systemic injection case with $24 \mathrm{~h}$ survival. Type II and type III fibrocytes are darkly stained in comparison with the organ of Corti. Type I fibrocytes are weakly stained. Arrowheads indicate darkly stained strial basal cells. The inset is a high magnification view of the $\mathrm{OHC}$ apex indicated by the small box. In this view the reaction product is confined to the region below the cuticular plate, which is indicated by the arrowhead. Scale bar $=100 \mu \mathrm{m}$. C. Local application case with $4 \mathrm{~h}$ survival showing granular reaction product in the $\mathrm{OHC}$ cytoplasm (arrowheads). Scale bar $=25 \mu \mathrm{m}$. D. Local injection case with $12 \mathrm{~h}$ survival showing dense staining in the bases (open arrowheads) and apices of OHCs. The plane of section was not parallel to the long axis of the cells and the section was somewhat tangential so that there appear to be 5 rows of OHCs. The paired bases (open arrowheads) and apices (above) are from different cells. The closed arrowhead indicates a clear cuticular plate above the dense apical reaction product. Scale bar $=25 \mu \mathrm{m}$. 


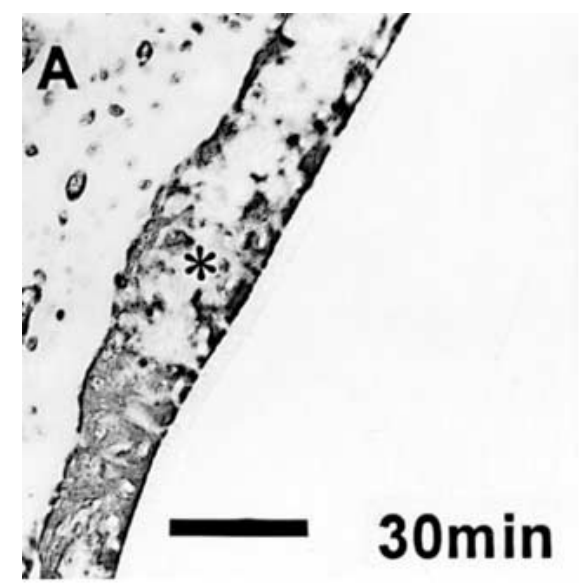

D

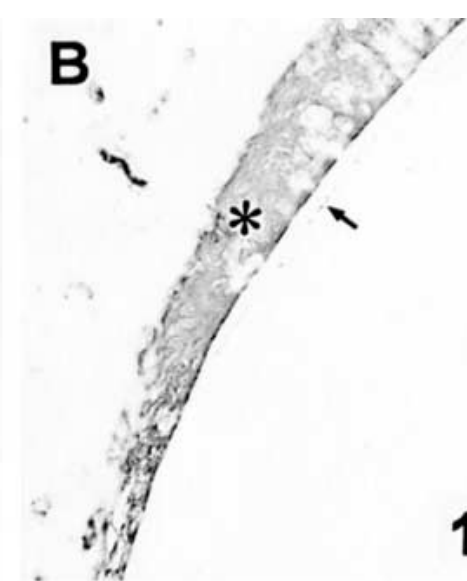

$\mathbf{E}$

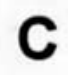

$12 \mathrm{~h}$

F.
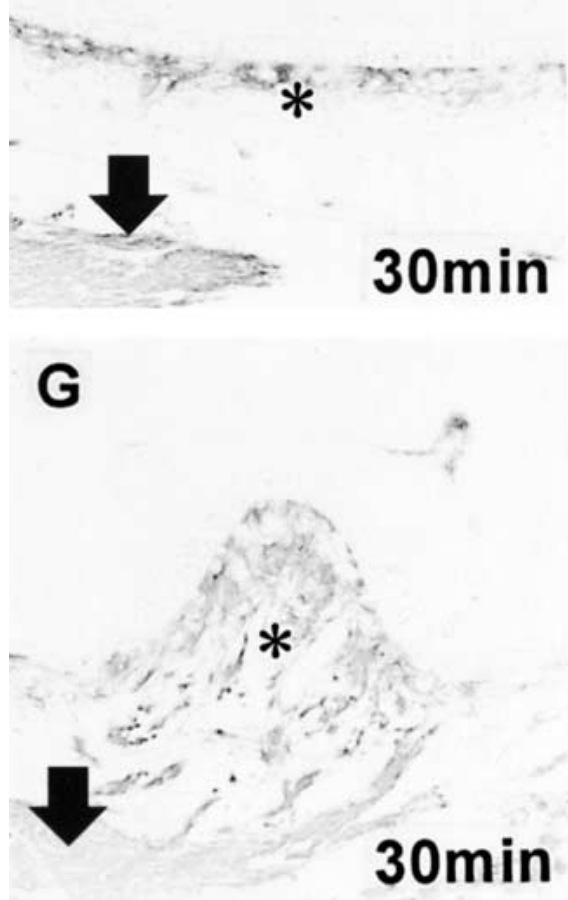

FIG. 3. Immunostaining for gentamicin in the vestibular organs following systemic application. (Numbers on the photos indicate survival periods.) Images in each row are of the same organs showing progressively less staining with increasing survival times. A, D, G. Fibrocytes of the connective tissue (asterisks) of the saccule (A), the utricle (D), and the lateral semicircular canal $(\mathbf{G})$ are immunoreactive for gentamicin, but hair cells are not positive. B, $\mathbf{E}, \mathbf{H}$. The apical regions (arrows) of hair cells of the saccule (B), the

the spiral ligament (area of the white arrowhead), but clear instances of spiral ligament cell loss were not apparent in every case where there was hydrops. However, cell loss is the extreme condition of toxicity and it may be necessary to seek evidence of more

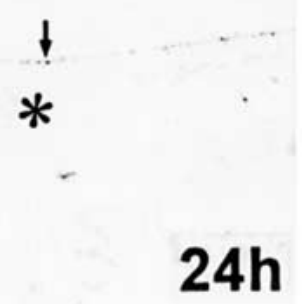

\section{H}

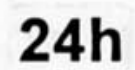

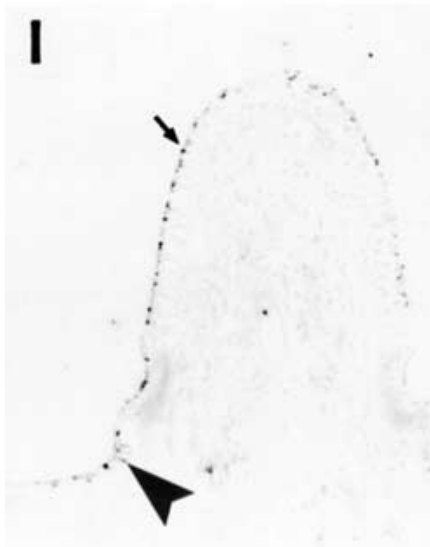

utricle $(\mathbf{E})$, and the crista of the lateral canal $(\mathbf{H})$ are positive for gentamicin. Fibrocytes (asterisk in $\mathbf{B}$ and $\mathbf{H}$ ) are also positive. $\mathbf{C}, \mathbf{F}, \mathbf{I}$. Only the apical portions (arrows) of hair cells of the saccule $(\mathbf{C})$, the utricle (F), and the lateral canal (I) are immunopositive for gentamicin. In addition, apical staining of transitional cells (arrowhead in I) was sometimes present. Large arrows in $\mathbf{D}$ and $\mathbf{G}$ indicate the vestibular nerve. Scale bar in $\mathbf{A}=100 \mu \mathrm{m}$.

subtle forms of cellular dysfunction that can account for hydropic conditions. Mild hydrops was present in two cases with 4 day survival and one case with 7 day survival. Longer-term survival cases with hydrops also showed fibrosis of scala vestibuli (Fig. 4G,H). 
A common form of degeneration was the complete loss of the organ of Corti and its replacement by a squamous epithelium (Fig. 4E,F,H). This condition was accompanied by degeneration of either the stria vascularis (Fig. 4E,H), and/or the spiral ligament (Fig. 4E,F,H), and/or the spiral limbus (Fig. 4G,H). There appeared to be no obvious relationships between the susceptibilities of cell loss in these different structures. The most severe form of degeneration included reduction of the membranous labyrinth to a squamous epithelium, accompanied by a complete fibrosis of the scala vestibuli (Fig. 4G,H). Fibrosis of the scala tympani invariably included some degree of degeneration of the spiral limbus (Fig. 4G,H). The most severe case of degeneration also included new bone formation in the spiral ligament and scala vestibuli, as well as on the middle ear surface of the otic capsule (Fig. 4H). In animals with greater than 1 week survival times and a totally absent organ of Corti, there was usually a clear reduction in the thickness of the adjacent stria vascularis (e.g., Fig. $4 \mathrm{E})$. In some cases the cross-sectional area of the stria was reduced in some cochlear turns and edematous or degenerated in other turns (e.g., Fig. 4H). Spiral ganglion cell loss appeared in parts of the cochlea where there was a totally degenerated organ of Corti. In contrast to other cell losses, ganglion cell loss was not usually apparent until survival times of one month or greater.

\section{Gentamicin distribution}

Application of gentamicin on the round window resulted in such high levels of the drug within the perilymph that it was difficult to differentially stain cells in the cochlea within $6 \mathrm{~h}$ post administration due to diffuse staining of all tissue. Consequently, the early time course of drug uptake could not be documented as precisely as in the systemically treated animals. As staining of extracellular tissue became reduced with increasing post administration time, diffuse staining of most cells was discernible. The cell types that were found to be positively stained for gentamicin following local administration were, by and large, the same cell types that were positive following systemic administration. A striking feature of locally treated cases was a marked basal to apical gradient in apparent drug uptake which corresponded to the drug application at the base of the cochlea. This gradient of staining matched the gradient of cellular degeneration which was most extreme basally.

There was variability between animals with respect to the degree of staining for gentamicin and in the extent of tissue that was stained. There was a strong correlation of the intensity of staining for gentamicin and the degree of cellular degeneration in individual cases. In cases of obvious cochlear degeneration, some cell types, such as root cells, which had stained only mildly in cases with no apparent degeneration, were intensely stained. The same relation was found in vestibular organs. In cases with missing vestibular cells, remaining nearby cells were far more intensely stained for gentamicin than corresponding cells in cases where there was no degeneration. Animals receiving the commercial solution of the drug usually had more intense immunostaining for gentamicin and more profound cell losses. There was no immunostaining for gentamicin and no obvious morphological changes in the animal which received the vehicle only.

There was considerable variability between animals in which sensory organs stained darkly for the drug when it was applied locally. Usually both the cochlea and vestibular organs were stained, but in some instances not all vestibular organs were stained, although there was no consistent pattern regarding which organs were stained. Usually when a given organ was heavily stained, perivascular tissue within the nearby bone was also stained.

\section{Organ of Corti}

Changes in the pattern of staining for gentamicin in the organ of Corti in locally treated animals followed the same sequence that occurred in systemically treated animals. That is, initially staining of OHCs was punctate and located in cytoplasm (Fig. 2C). More diffuse staining, often with a reticular appearance, was present at $12 \mathrm{~h}$ and beyond (Fig. 5A). Gradually the cytoplasmic staining diminished with increasing survival times except for that in the infracuticular portions of the OHCs (Fig. 5A-D). Apical staining of OHCs was present in animals with survival times as long as 6 months (Fig. 5D). Staining present at the longest survival time was predominantly in the basal turn. In animals in which the organ of Corti was collapsed and replaced by cuboidal epithelium, the remaining cells were immunoreactive for gentamicin at survival times of 1 month or greater (Fig. 5E,F). In contrast, when only a squamous epithelium remained, it showed little or no staining for gentamicin (not illustrated).

\section{Spiral ganglion}

Ganglion cells were darkly stained with punctate reaction product at post injection times of 4 days and less. At longer post injection times, use of the standard dilution of the antibody $(1: 40,000)$, which resulted in intense staining of type III fibrocytes, produced little or no staining of ganglion cells. 

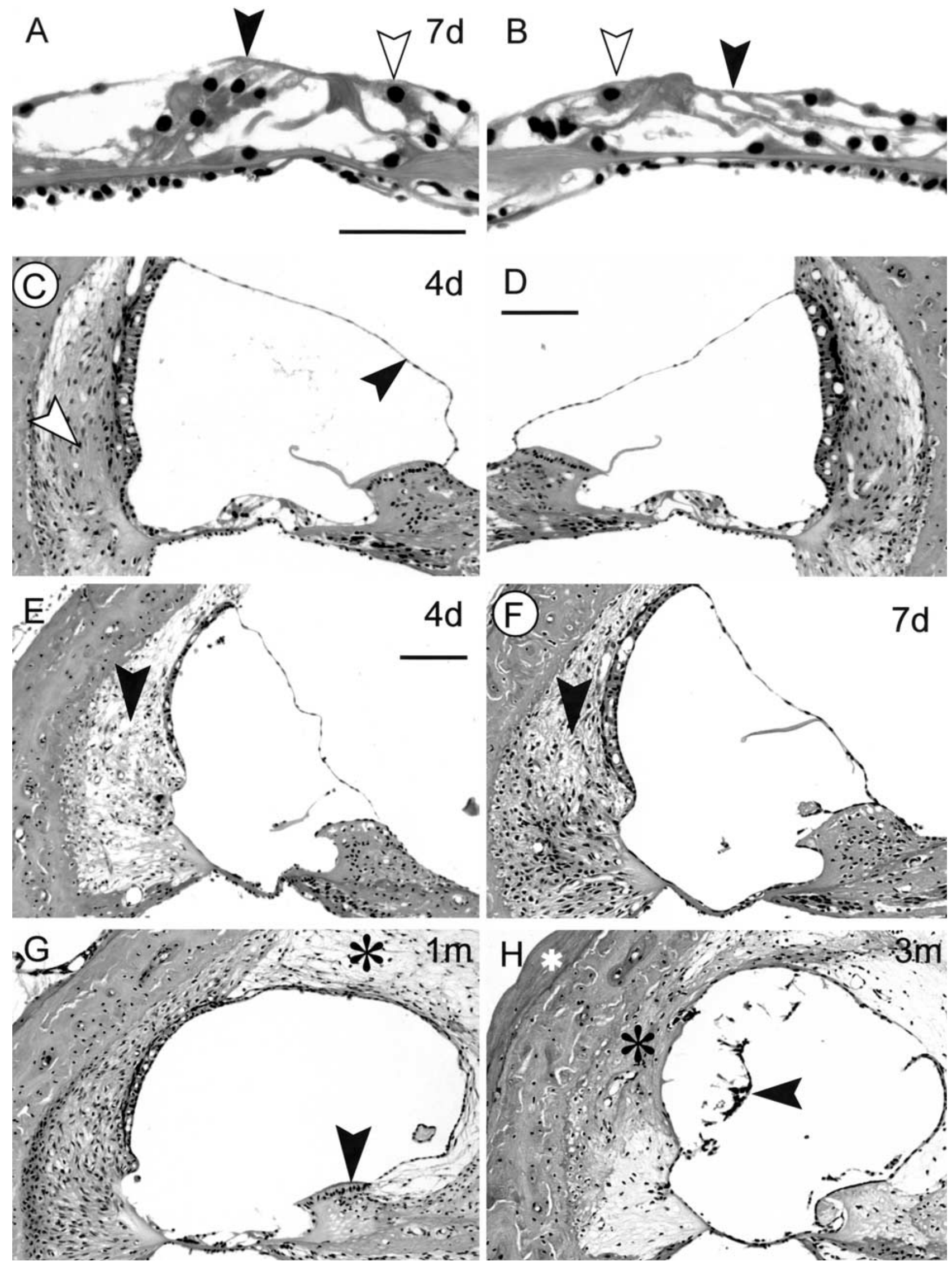


\section{Basilar membrane}

Mesenchymal cells beneath the basilar membrane (arrowheads in Fig. 5A-F) were immunoreactive at 6 $\mathrm{h}$ post administration. This staining was present throughout the length of the basilar membrane, but only cells in basal turn remained stained for as long as 6 months (Fig. 5D). Staining of the mesenchymal cells was present regardless of whether the overlying organ of Corti was degenerated (Fig. 5E,F). Nearby mesenchymal cells lining the scala tympani were often intensely stained.

\section{Lateral wall}

There was distinct staining in the basal cells and intermediate cells of the stria vascularis at $6 \mathrm{~h}$ post administration (Fig. 5G, arrowhead), but no staining of these cells remained beyond 1 week survival (Fig. $5 \mathrm{H}, \mathrm{I})$. In ears with a badly damaged organ of Corti, there was granular staining of the marginal cells of the stria vascularis (arrowhead in Fig. 5J). The spiral ligament was diffusely stained at $6-24 \mathrm{~h}$ post administration (not illustrated). Diffuse staining initially obscured individual cells, but distinct staining of type I fibrocytes, which was present chiefly in the basal half of the cochlea, was obvious at 4 days post administration (Fig. 5G, region of the asterisk). This staining was more pronounced than in systemically treated animals but was diffuse instead of punctate as in most other cells. Staining of type I fibrocytes was considerably diminished at 7 days survival (Fig. 5H). Staining of type II fibrocytes was predominantly in the basal turn. This staining was punctate and intense.
Many stained type II fibrocytes were present at survival times up to 1 week. Thereafter, the number of stained type II fibrocytes declined and only a few were present at 1 month post administration (small arrows in Fig. 5H,I). Staining of type III fibrocytes (large arrows in Fig. 5G-J) was predominantly in the basal turn. These cells were the most avid cochlear cells in accumulating locally applied gentamicin. In several cases where there was very little staining of the cochlea, type III fibrocytes were the only cochlear cells that were stained. Unlike OHCs, which avidly accumulated the drug and were highly susceptible to degeneration, type III fibrocytes were clearly the most robust in the presence of high levels of accumulated gentamicin. They stained intensely soon following administration and remained so for as long as 6 months (Fig. 5J). Despite this avid accumulation of the drug, in the most severely degenerated cases, these cells were the only remaining identifiable cell type within the cochlea.

External sulcus cells and root cells within the spiral ligament were stained predominantly in the basal and second turns, but sometimes in the third and apical turns (small arrows in Fig. 5H,I). Staining of external sulcus cells was always less intense than that of root cells, which extend into the ligament from the external sulcus cells. In contrast to systemically injected cases where root cells were seldom darkly stained, in locally treated animals, root processes were often darkly and diffusely stained (small arrows in Fig. $5 \mathrm{H}, \mathrm{I})$. Such staining occurred in regions adjacent to sites of degenerated or totally missing organ of Corti and was present in cases with as long as 3 months survival.
FIG. 4. H\&E staining of cochleas treated with local application of gentamicin. The pair of images at the top are from the upper basal turn and show a gentamicin-treated ear $(\mathbf{B})$ and the corresponding image of the contralateral control ear $(\mathbf{A})$ in a case with minimal degeneration. The open arrowheads indicate IHCs, closed arrowheads indicate OHCs. On the treated side both OHCs and Deiters' cells are missing and the height of the organ is considerably reduced. Scale bar $=50 \mu \mathrm{m}$. C, D. Treated $(\mathbf{C})$ and untreated control (D) cochleas from a case with minimal overt tissue damage but endolymphatic hydrops, as indicated by the bulging Reissner's membrane (closed arrowhead in $\mathbf{C}$ ). The white arrowhead indicates a site of apparent cell loss within the spiral ligament. The artificial perilymph formulation of gentamicin was used in this case. In all other cases shown in this figure except for $\mathbf{E}$, the gentamicin for injection formulation was applied to the round window. Calibration bar in $\mathbf{D}=100 \mu \mathrm{m}$ and applies to $\mathbf{C}$ and $\mathbf{D}$. E. A 4 day survival case with complete destruction of the organ of Corti and disruption of other epithelial cells except for the stria vascularis, which is shrunken. In $\mathbf{E}$ and $\mathbf{F}$ the organ of Corti has been replaced by a squamous epithelium. The nuclei of the squamous cells are present on the superior surface of the basilar membrane. The arrowheads in the spiral ligament of $\mathbf{E}$ and $\mathbf{F}$ indicate sites of cell loss, which shows obvious cell loss (compare with $\mathbf{E}$ and $\mathbf{F}$ with $\mathbf{G}$ ). This was the most extreme case of degeneration seen in animals treated with the gentamicin formulated in artificial perilymph. Scale bar $=100 \mu \mathrm{m}$ and applies to E-H. F. A case in which the membranous labyrinth was reduced to a squamous epithelium, except for strial marginal cells. There may be mild cell loss in the spiral ligament (region indicated by the arrowhead). G. A case with less destruction of epithelial cells than shown in $\mathbf{E}$ and $\mathbf{F}$ as evidenced by pillar cells in the organ of Corti and interdental cells, indicated by the arrowhead. There was little apparent cell loss in the spiral ligament but there was endolymphatic hydrops and the scala vestibuli was completely filled with fibrotic tissue (asterisk). H. The most advanced degeneration seen following gentamicin administration. The membranous labyrinth has been reduced to a squamous epithelium, including the stria vascularis. The debris indicated by the arrowhead appears to be the remains of the stria vascularis. There was endolymphatic hydrops, fibrosis of the scala vestibuli, and new bone formation. The white asterisk indicates new bone formed on the middle ear side of the otic capsule. The black asterisk indicates new bone that has replaced part of the spiral ligament. Numbers in the photos indicate survival periods. 


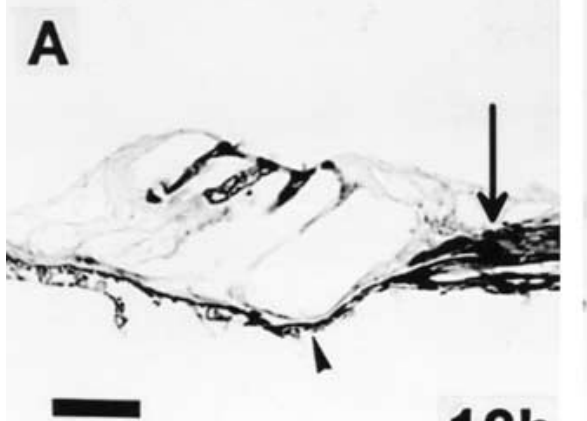

12h

D

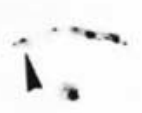

E
B
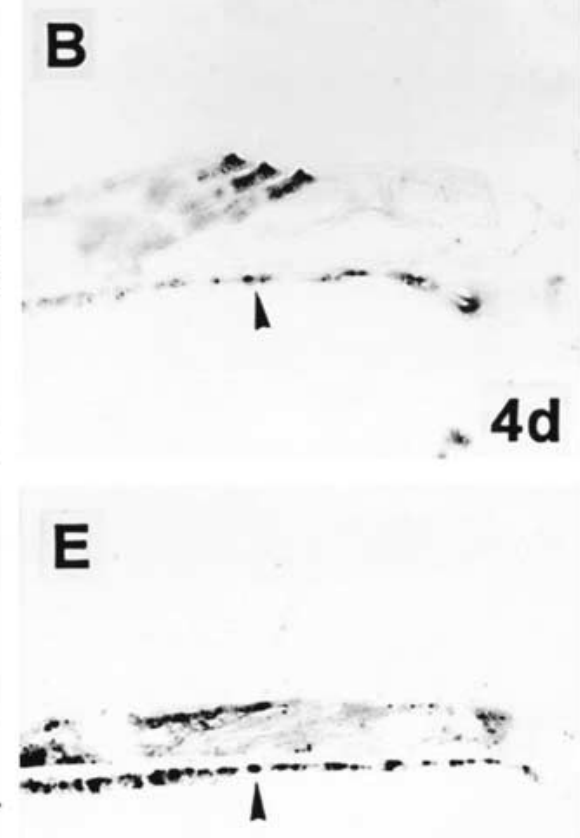

$6 m$

G
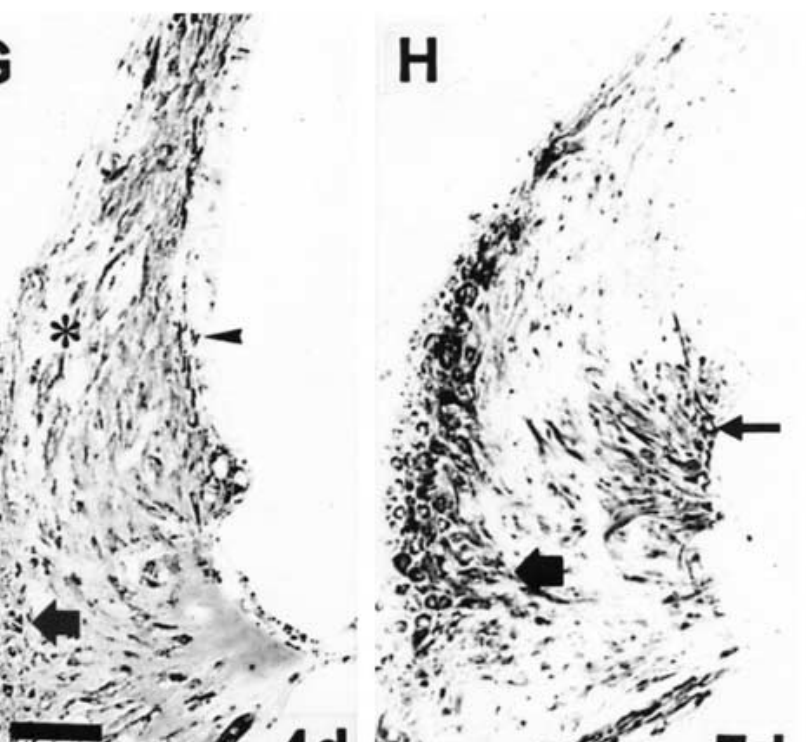

4d
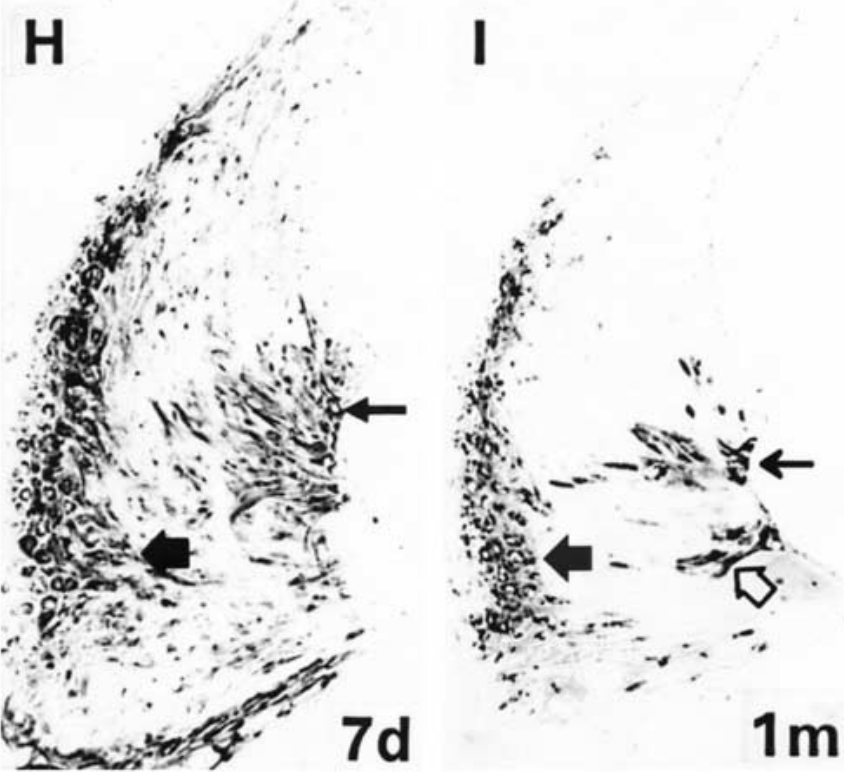

isifer
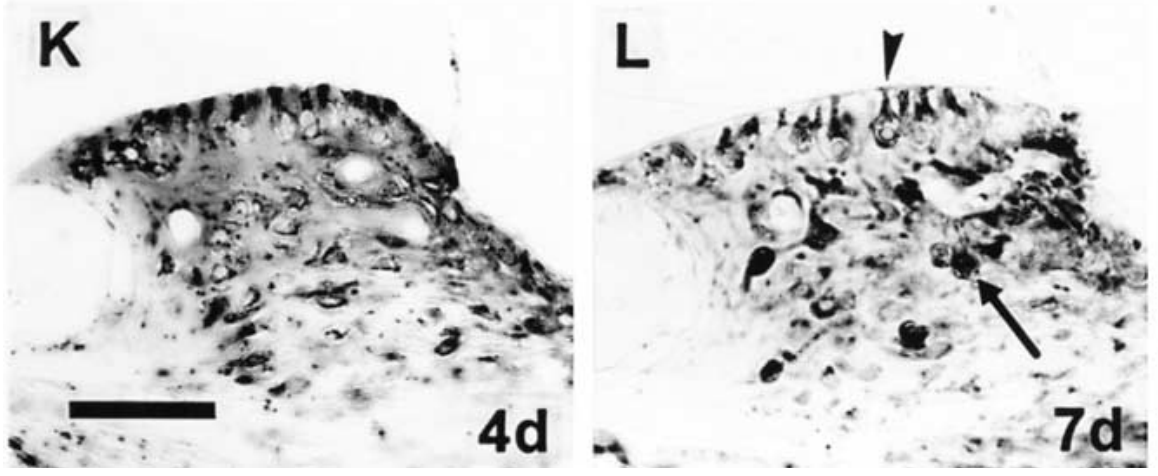

C

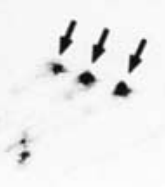

7d

F

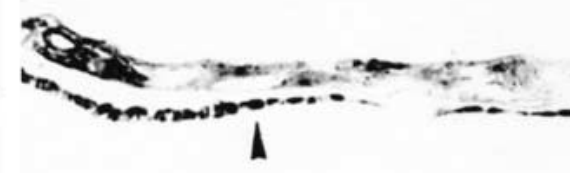

$1 \mathrm{~m}$

$3 m$

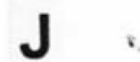

$1 \mathrm{~m}$

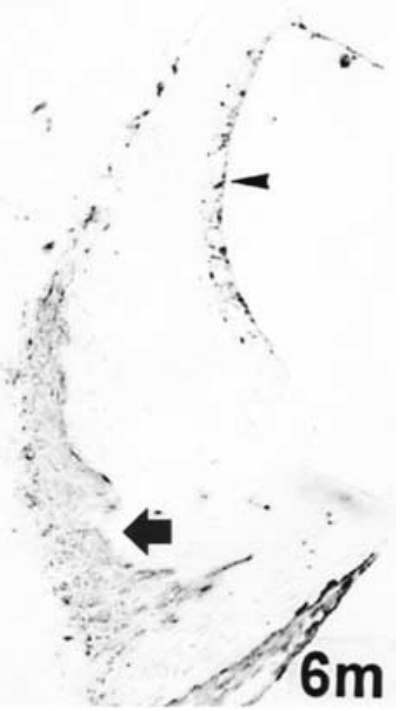

M

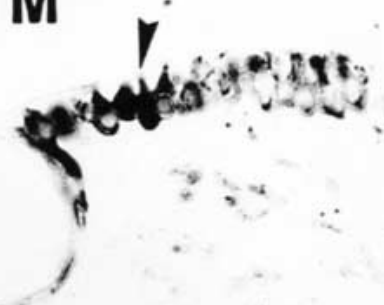




\section{Spiral limbus}

The spiral limbus was darkly and diffusely stained in all turns at short survival times. At 4 days post administration the extracellular diffuse staining was sufficiently eliminated to show that both fibrocytes (arrow in Fig. 5L) and interdental cells were stained (Fig. 5K). Dark staining was present in interdental cells (arrowheads in Fig. 5L,M) longer than in fibrocytes. Punctate staining of both cell types was present as long as 6 months in all cochlear turns. Irregular diffuse staining also remained in the limbus for as long as 6 months.

\section{Vestibular system}

The patterns of immunostaining in vestibular organs were similar to those seen in systemically treated animals. There was diffuse immunostaining in the subepithelial connective tissue of all of the vestibular organs at $6 \mathrm{~h}$ post administration (asterisks in Fig. $6 A, D, G)$. This staining gradually diminished with increasing survival time. In contrast, staining of hair cells, which was clearly evident at $24 \mathrm{~h}$, became increasingly distinct. Staining of hair cells was present in the cytosol and the stereocilia of some animals with $24 \mathrm{~h}$ (not shown) and 4 day survival times (Fig. $6 \mathrm{~B}, \mathrm{E}, \mathrm{H})$. In animals with longer survival times, staining of hair cells was restricted to the region beneath the cuticular plate and was present for as long as 6 months post administration (Fig. 6C,F,I). In comparison to staining intensities of hair cells, there was weak staining in vestibular ganglion cells in animals with less than 4 days survival (not illustrated).

\section{DISCUSSION}

The present findings extend the numerous previous studies of cochlear aminoglycoside uptake and toxicity in three principal ways: (1) Following gentamicin administration by local or systemic administration, virtually all cochlear cells were found to accumulate the drug and to retain it for periods that varied widely between different cell classes. (2) Following a single local application of gentamicin, virtually all cochlear cells were vulnerable to degeneration. (3) The degree of cell destruction following local gentamicin administration was strongly correlated with the extent of staining for gentamicin in the surviving cells, which suggests that variability in toxicity between animals was probably largely determined by variability in the extent of local gentamicin uptake. These findings demonstrate that aminoglycoside uptake and toxicity are not limited to sensory cells and indicate that a more comprehensive view is necessary for understanding the breadth of this important problem. The findings also set the stage for the accompanying article, which documents cytochemical changes in cells that survive gentamicin administration.

Accumulation of aminoglycoside drugs in sensory cells of the inner ear has been documented by many investigators (Balogh et al. 1970; Portmann et al. 1974; Hayashida et al. 1985; Veldman et al. 1985; Hayashida 1989; DeGroot et al. 1990; Hiel et al. 1992a,b, 1993; Iwamori et al. 1994; Hashino and Shero 1995; Hashino et al. 1997; Aran et al, 1999). Due to sensitivity limitations of the previously utilized assays, most studies of the distribution of accumulated aminoglycoside were performed in the chronically treated animals, an experimental design which complicates interpretation of uptake kinetics. Hayashida (1989) reported immunostaining for gentamicin within the cochlea following a single intratympanic application but the description of positive cells was limited and no images of cochlear cells were presented. Therefore, detailed comparisons with that study are not possible. In the present study, a sensitive immunostaining technique made it possible to detect immunostaining for gentamicin for extended periods after a single systemic or local application. A single administration was used because the experimental design offers a simpler
FIG. 5. Immunostaining for gentamicin in the cochlea following local application. Numbers on the photos indicate survival periods. A. The cytosol of OHCs shows intense immunoreaction for gentamicin. The arrow indicates heavily stained radial nerve fibers. B. OHC cuticular plates and supranuclear cytosol are immunoreactive for gentamicin. C, D. Only the subcuticular plate regions are positive for gentamicin. E, F. The partially collapsed organ of Corti shows inmunostaining for gentamicin. In $\mathbf{A}-\mathbf{F}$, the mesenchymal cells beneath the basilar membrane (arrowheads) show intense immunostaining. In G-J, immunostaining for gentamicin in the lateral wall of the cochlea shows different patterns depending upon survival periods. G. All fibrocytes in the spiral ligament show intense immunostaining. The asterisk indicates the type I fibrocyte region. Basal cells and intermediate cells (arrowhead) of the stria vascularis are immunoreactive. H. Type II fibrocytes and root cells (small arrow) and type III fibrocytes (large arrow) of the spiral ligament are immunoreactive. I. Root cells (open arrow and small arrow) and type III fibrocytes (large closed arrow) of the spiral ligament are immunoreactive. J. Type III fibrocytes (large arrow) are immunoreactive. The marginal cells of the stria vascularis (arrowhead) are positive in this case, which had organ of Corti destruction. K, L, M. The spiral limbus shows different patterns of immunostaining for gentamicin depending upon survival periods. $\mathbf{K}$. There is diffuse staining within the entire spiral limbus. L. The fibrocytes (arrow) and interdental cells (arrowhead) are immunoreactive. M. Interdental cells (arrowhead) are positive. A, $\mathbf{K}, \mathbf{L}$, and $\mathbf{M}$ are from second turn, others are from basal turn of the cochlea. The scale bar in $\mathbf{A}=20 \mu \mathrm{m}$ and applies to $\mathbf{A}-\mathbf{F}$. The calibration bar in $\mathbf{G}=\mathbf{5 0} \mu \mathrm{m}$ and applies to the $\mathbf{G}-\mathbf{J}$. Scale bar in $\mathbf{K}=50 \mu \mathrm{m}$ and applies to the $\mathbf{K}-\mathbf{M}$. 

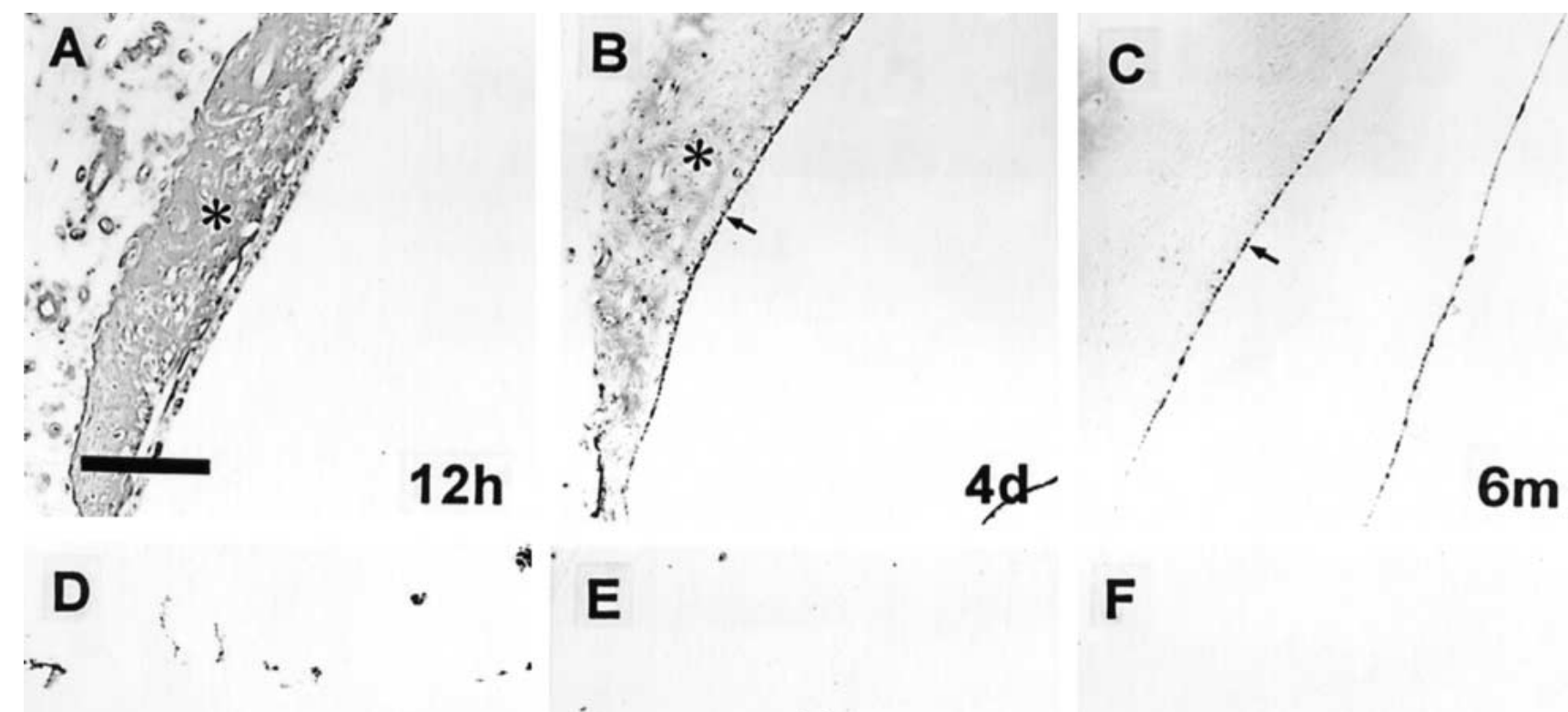

औ.
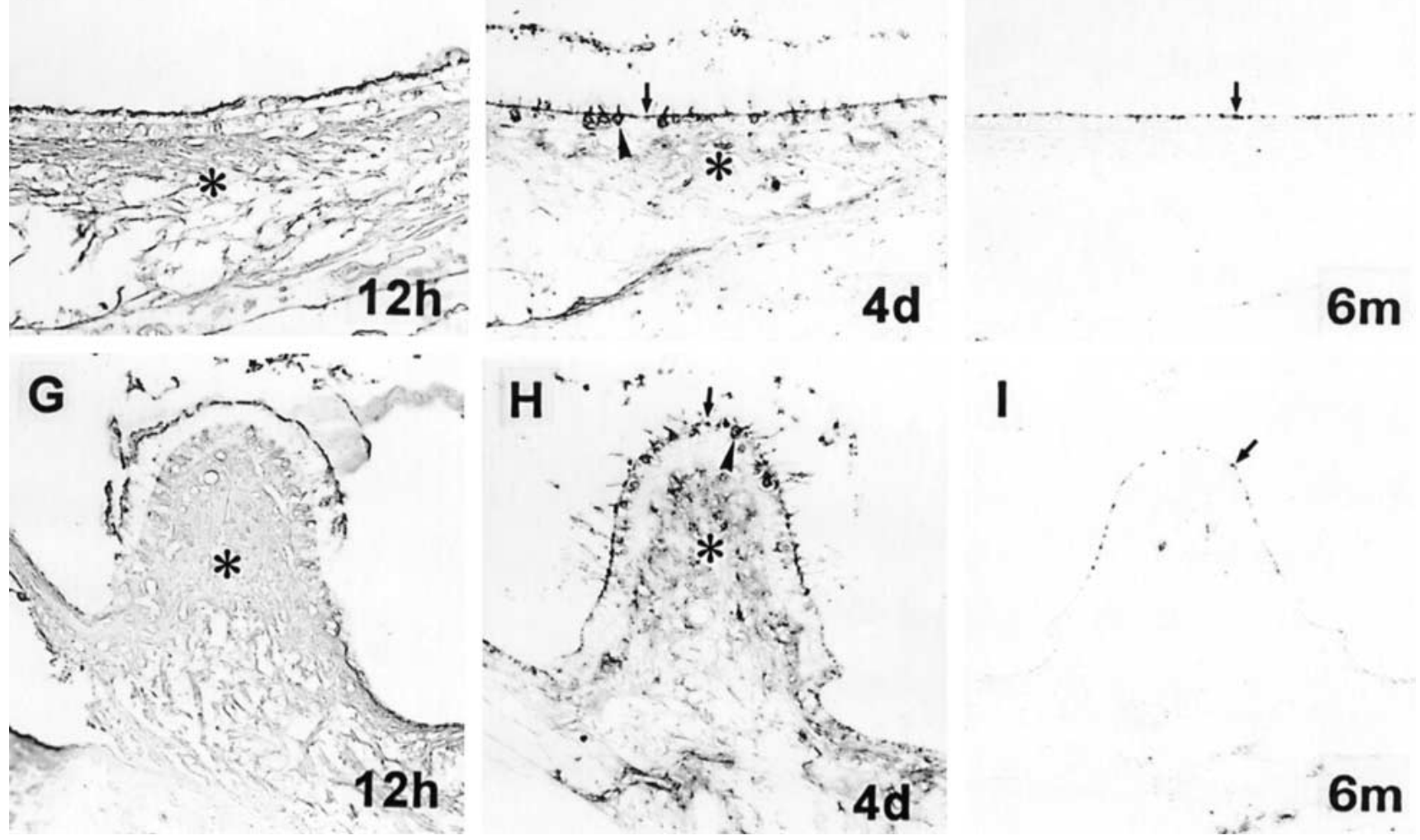

$6 m$

FIG. 6. Immunostaining for gentamicin in the vestibular system following local application. Numbers on the photos indicate survival periods. Each row shows the progression of staining with increasing survival time for a given tissue. A, D, G. Hair cells and fibrocytes (asterisk) in the subepithelial connective tissue of the saccule (A), the utricle (D), and crista of the lateral canal $(\mathbf{G})$ are intensely positive for gentamicin. B, E, H. The apical portions of hair cells (arrows) of the

process to analyze. Repeated doses, which could mask or otherwise affect the dynamics of drug uptake and disposition, were avoided. The results provide an extended view of the time course of the disposition of the drug and of details regarding the identity of cells saccule $(\mathbf{B})$, the utricle $(\mathbf{E})$, and crista of the lateral canal $(\mathbf{H})$ show intense immunoreaction. Fibrocytes (asterisks) are weakly immunoreactive. In the utricle $(\mathbf{E})$ and lateral canal $(\mathbf{H})$, the cytosol of hair cells (arrowheads) is immunostained. C, F, I. The apical portions of hair cells (arrowheads) of the saccule $(\mathbf{C})$, the utricle $(\mathbf{F})$, and crista of the lateral canal (I) are immunoreactive. In $\mathbf{C}$ the vestibular membrane is also positive. Scale bar $=100 \mu \mathrm{m}$.

that accumulate the drug following a single dose. Retention of the drug was found to vary markedly between individual cell types (Fig. 7).

In both locally and systemically treated animals, staining for gentamicin was strongest and persisted 


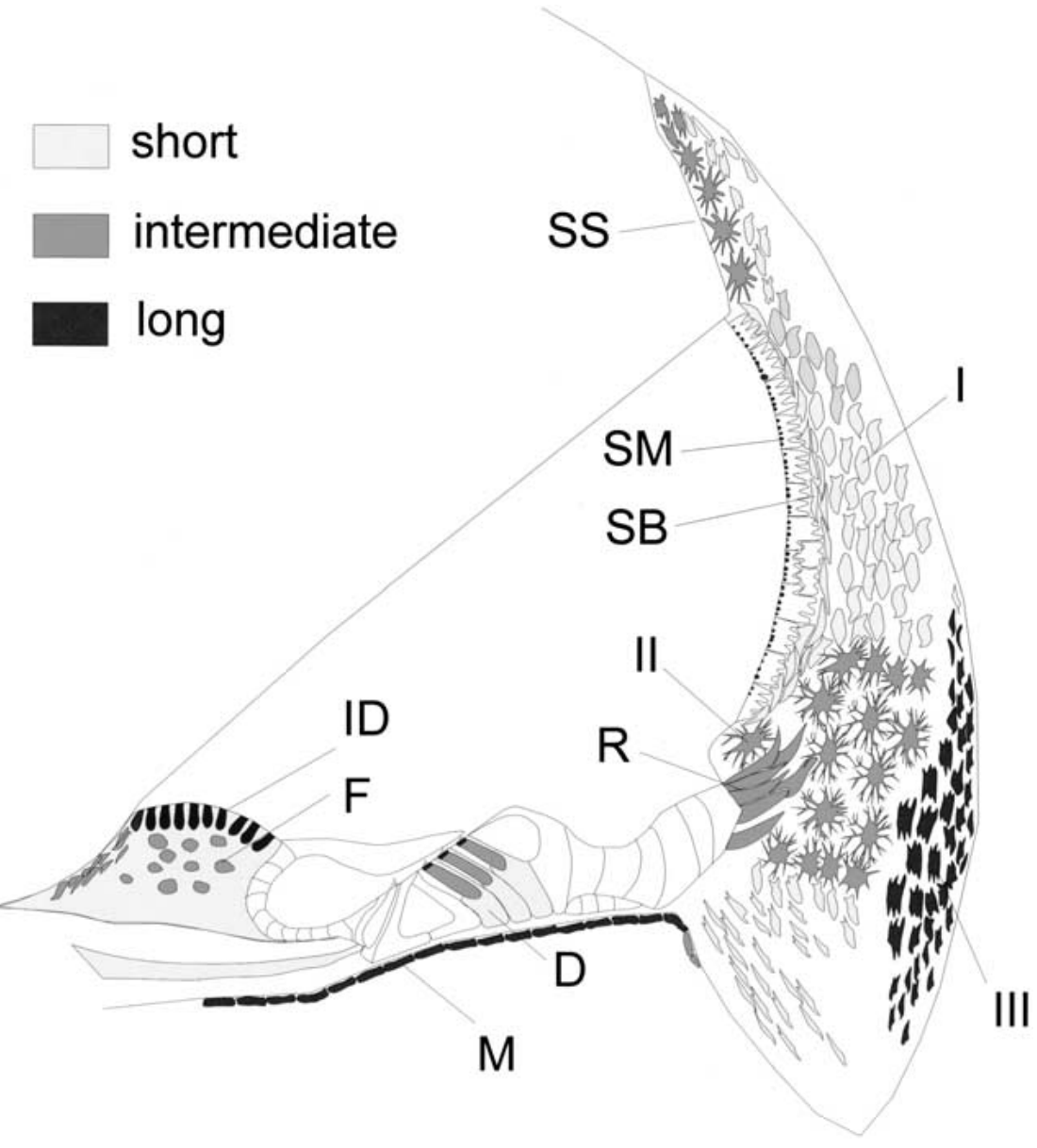

FIG. 7. A schematic illustration of gentamicin uptake and retention in cells within the basal turn following local application. The affinity of cells for gentamicin was strongly correlated with duration of retention. The shading code indicates the duration after administration for which gentamicin immunostaining was present. The cytosol of inner hair cells and most supporting cells showed weak retention of gentamicin. The infracuticular plate region of $\mathrm{OHCs}$, the mesenchymal cells $(M)$ beneath the basilar membrane, interdental cells (ID) of the spiral ligament, and type III fibrocytes (III) showed high affinity and long-term retention. Outer sulcus cells, adjacent root cells (R), type II fibrocytes (II), fibrocytes (F) of the spiral limbus, and strial marginal cells (SM) showed intermediate affinity and retention of gentamicin. Type I fibrocytes (I), strial basal cells (SB), strial intermediate cells (SI), and Deiters' cells (D) showed low affinity for and brief retention of gentamicin.

longer in cells in the basal turn of the cochlea. No evidence of tissue damage was apparent in systemically treated animals or in some animals given a single local application of gentamicin dissolved in artificial perilymph. Following a single round window application of gentamicin, the degree of immunostaining varied between animals and cellular degeneration varied widely, ranging from mild (a few missing OHCs and Deiters' cells) to severe (total destruction of the cochlea). Only cases that had severe morphological damage after local application showed intense immunostaining of root cells, strial marginal cells, and interdental cells. The unusually dark staining of surviving cells that accompanied loss of the organ of Corti suggests that there was greater local uptake of the drug in those cases and this resulted in the severity of toxicity. Hence, variability in the severity of gentamicininduced tissue destruction may have been a reflection of a corresponding variability in local tissue uptake. High variability between animals in susceptibility to degeneration has been observed since the earliest studies of aminoglycoside toxicity. The present results indicate that variability in toxicity may be due to variability in accumulation of the drug rather than in differences in animals' capacity to systemically metabolize the drug or its products (Schacht 1993).

Local application of the drug produced much more intense immunostaining for gentamicin than systemic administration and sometimes resulted in destruction of the inner ear. These results are in apparent contrast to a report that application of smaller amounts of gentamicin on the round window resulted in no hearing loss (Conlon et al. 1998). In the present study, the intensity of immunostaining and morphological damage in animals that received the commercial solution were usually, but not always, greater than in animals that received the drug dissolved in artificial perilymph solution. The artificial perilymph and the commercial solution had different $\mathrm{pH}$; this may have affected drug stability or round window membrane permeability. The vehicle of the commercial solution contained stabilizers not present in the artificial perilymph so that the effective dosage may have been prolonged for that formulation.

\section{Hair cell uptake}

The results show that gentamicin is avidly taken up by all cell types within the labyrinth and that some cells 
remain immunoreactive for the drug for as long as six months. The sensitivity of the immunostaining procedure apparently made it possible to detect gentamicin-like immunostaining in far more structures for longer periods than previous reports of aminoglycoside uptake in the cochlea as seen by immunostaining (Hayashida et al. 1985; Veldman et al. 1985; Yamane et al. 1988; DeGroot et al. 1990; Hashino and Shero 1995). It is difficult to directly compare the present results with those of previous reports because the latter used either multiple administrations of drugs or gave aminoglycosides in combination with other drugs, because previous reports paid little attention to cells other than hair cells, and because the sensitivity of the present assay was far greater than those previously utilized. Nevertheless, long-term retention of gentamicin (or a metabolic product containing the epitope recognized by the antibody) by hair cells has been reported previously following repeated systemic administration (Hiel et al. 1992a; Dulon et al. 1993). In keeping with those findings, the present results showed that long-term retention in OHCs was consistently compartmentalized to the apex of the cells. Accumulation in the infracuticular region of gentamicin (DeGroot et al. 1990) and of horseradish peroxidase (Seigel and Brownell 1986; Leake and Snyder 1987) has been previously reported. This zone also avidly accumulates a fluorescent compound (FM 1-43) that is reported not to be accumulated by nonsensory cells (Meyer et al. 2001). The latter authors referred to the zone of accumulation as Hensen's body and suggested that it was a specialized site in OHCs for membrane degradation and turnover. Based upon the association of tritiated gentamicin within "granules resembling lysosomes" (DeGroot et al. 1990), it has been assumed that lysosomal degradation of endocytosed aminoglycosides occurs at this site. On the other hand, the extremely long retention of gentamicin-like antigens at this site (Hiel et al. 1992a; present study) suggests that gentamicin may be sequestered here and perhaps protected from degradation and that gentamicin bound here need not be fatal to OHCs. The structure of the infracuticular zone has recently been well documented and termed the "canalicular reticulum" (Spicer et al. 1998). The long-term apparent association of gentamicin with this organelle in OHCs may be coincidental, as suggested by the presence of similar organelles in numerous other cochlear cells that do not retain gentamicin (Spicer and Schulte 1997).

Granular cytosolic staining in the OHCs was the first evidence of their accumulating gentamicin. Only later was there pronounced localization in the infracuticular zone. The initial appearance of the drug basolaterally indicates that the drug was absorbed through the basolateral membrane. This conclusion contrasts with those of previous studies that were interpreted as indicating that aminoglycosides enter hair cells apically (Hashino and Shero 1995; Richardson et al. 1997). Hashino and Shero visualized the localization of systemically administered tritiated kanamycin in avian ears using electron microscopy and found accumulation of the drug in apical portions of OHCs $12-18 \mathrm{~h}$ post administration. The present findings are in accord with those of Hashino and Shero (1995) in that at $12 \mathrm{~h}$ post administration there was immunostaining for gentamicin apically within OHCs. However, at earlier survival times granular staining for gentamicin was present basolaterally before pronounced apical staining occurred, a finding which favors the idea of basolateral accumulation. Based on in vitro experiments, Richardson et al. (1997) concluded that gentamicin was accumulated by apical hair cell membranes but evidence for that conclusion was indirect. In the present study many cells that accumulated gentamicin were not epithelial and have no apical membrane through which to accumulate the drug. Clearly apical specializations are not required for gentamicin uptake. Nevertheless, more direct observations are needed to settle the issue of where gentamicin is accumulated by hair cells.

\section{Nonsensory cell uptake}

In addition to hair cells, the present study showed that virtually all cochlear cells take up gentamicin and are vulnerable to degeneration following local application of gentamicin. Previous studies have reported total destruction of the organ of Corti following middle ear administration of aminoglycosides (e.g., Wersall et al. 1969). In addition, following repeated parenteral gentamicin administration, type II fibrocytes, which were referred to as pericapillary tissue, were found to be degenerated (Hawkins 1973). As in previous studies, in the present study, OHCs, together with associated supporting cells, were clearly highly vulnerable. However, widespread loss of cells within the spiral ligament and spiral limbus also occurred within a week of local application of the drug. The early degeneration of these cells suggests that degeneration was not secondary to the drug's effects upon cells of the organ of Corti. Indeed, Hawkins (1973) has suggested that aminoglycoside-induced damage to cells within the spiral ligament may make sensory cells more vulnerable to damage by ototoxic drugs. Results of Kimura et al. (1991) are in keeping with this suggestion. In addition, the presence of endolymphatic hydrops in ears with minimal cell loss at early survival times indicated that some form of pathology of nonsensory cells was induced by local 
administration of gentamicin. The identity of the affected cells was not apparent.

The present findings indicate that all cochlear cells take up gentamicin irrespective of the route of administration and that accumulation makes all cells vulnerable to gentamicin-induced toxicity. Previous work has shown that aminoglycosides are accumulated by nonsensory cells of the organ of Corti and mesenchymal cells beneath the basilar membrane (Hayashida et al. 1985; Yamane et al. 1988; DeGroot et al. 1990). Except for spiral ganglion cells, the time course of degeneration of nonsensory cells was apparently not very different from the time course of hair cell degeneration. This suggests that degeneration of epithelial cells and connective tissue cells was due to direct effects of the gentamicin upon those cells rather than their degeneration being secondary to sensory cell loss. In the case of ganglion cells, immunostaining results indicated that they showed modest uptake and short retention of gentamicin. Moreover, unlike most cells, ganglion cell loss was not apparent soon after drug administration and loss occurred only in regions of the cochlea where there was complete destruction of the organ of Corti. These observations suggest that ganglion cell survival may depend upon trophic factors generated by cells of the organ of Corti (see e.g., Gao 1998; Marzella and Clark 1999). The sparse and brief staining of ganglion cells for gentamicin is in keeping with this interpretation.

Avid accumulation of gentamicin and retention of it (or its metabolic product) were not good predictors of a given cell type's vulnerability. In particular, type III fibrocytes accumulated gentamicin more avidly than hair cells; they retained it for extended periods, and yet were the most resistant of all cells within the cochlea to gentamicin-induced degeneration. Perhaps type III fibrocytes sequester gentamicin in a manner similar to that of the apical concentrations seen in OHCs and this sequestration accounts for the long-term retention of as well as the cells' resistance to toxic effects of gentamicin.

The extended periods of post administration staining for the drug remain to be explained. The epitope recognized by the antigentamicin remained in certain cells for prolonged periods but there is no direct means of determining if the staining sites were representative of complete gentamicin molecules or merely degradation products. The fact that OHCs, which are among the cochlear cells that are most vulnerable to gentamicin toxicity, were one of the cell types that remained positive for gentamicin-like staining for the longest survival times indicates that if the gentamicin remained intact within the cells, it must have been sequestered from the intracellular site(s) that make the cells vulnerable to the toxic effects of gentamicin. It is not clear if cells that showed no evidence of long-term post administration retention either (1) completely metabolized the drug, (2) had degenerated and were no longer present, or (3) failed to accumulate sufficient amounts of the drug for it to be detected.

\section{Clinical implications}

Treatment of patients with local application of gentamicin also shows a high degree of variability (see, e.g., Blakley 2000). Until the factors controlling variability are isolated and controlled, it may be expected that for treatment of patients with local administration of gentamicin it will continue to be necessary to titrate dosages and that extreme toxic effects of initial doses may occur in the cochlea. Recent variations of the present approach to local application, utilizing a piece of gelfoam soaked in gentamicin to retain the drug on the round window (Husmann et al. 1998) or implanting a catheter to slowly release the drug (DeCicco et al. 1998), may reduce intersubject variability.

One extreme reaction to the drug observed in the present study was fibrosis and osteoneogenesis of the scala tympani. These effects were not accompanied by infiltration of inflammatory cells but were apparently proliferative reactions of mesenchymal cells that line the scalae or of cells of the spiral limbus in response to perturbation by exceptionally high effective doses of gentamicin. The two extreme cases of fibrosis were accompanied by wholesale cell loss and certainly by total hearing loss. Obviously it would be desirable to avoid such reactions in patients being treated for dizziness. The present results indicate the need for caution in selecting conservative doses and treatment regimens so as to avoid destruction of the cochlea. Even the most conservative doses of locally applied gentamicin can be expected to result in cochlear hair cell and supporting cell loss, especially within the basal turn. In humans, damage restricted to the base of the cochlea may not be detected by routine audiometry because high-frequency sensitivity, which is localized to this region, is not normally tested. Loss of high-frequency sensitivity may be an acceptable price to pay for relief from vestibular symptoms. Further experimental studies are needed to determine if it is possible to adjust drug dosages so that vestibular cells accumulate significant amounts of gentamicin without simultaneous destruction of cochlear cells.

Research on hair cell regeneration in birds following gentamicin administration (see, e.g., Cotanche 1999; Stone and Rubel 2000) has opened prospects for eventual development of treatments to induce hair regeneration in humans who have been deafened by aminoglycoside treatment for infections or for intractable dizziness. The present results indi- 
cate that in mammals the scope of tissue requiring regeneration following aminoglycoside toxicity could extend to all cochlear cell classes. Consequently, the problem of repairing aminoglycoside-damaged ears will prove to be considerably more complex than is generally conceded.

\section{ACKNOWLEDGMENTS}

This work was supported by NIH grant DC 03929. The authors are grateful to M.C. Liberman, J.B. Nadol, Jr., and W.F. Sewell for helpful comments on the manuscript.

\section{REFERENCES}

AdAms JC. Biotin amplification of biotin and horseradish peroxidase signals in histochemical stains. J. Histochem. Cytochem. 40:1457-1463, 1992.

Aran JM, Erre JP, Lima da Costa D, Debbarh I, Dulon D. Acute and chronic effects of aminoglycosides on cochlear hair cells. Ann. N. Y. Acad. Sci. 884:60-68, 1999.

Balogh K, Hiraide F, Ishi D. Distribution of radioactive dihydrostreptomycin in the cochlea-an autoradiographic study. Ann. Otol. (St. Louis) 79:641-652, 1970.

BLAKLEY BW. Update on intratympanic gentamicin for Meniere's disease. Laryngoscope 110:236-240, 2000.

Brummett RE, Traynor J, Brown R, Himes D. Cochlear damage resulting from kanamycin and furosemide. Acta Otolaryngol. 80:86-92, 1975.

Bryant GM, Cronin-Schreiber R, Alexander A, Norris CH, Quine PS, GuTH PS. The potentiation of ototoxicity when aminooxyacetic acid and kanamycin are co-administered. Hear. Res. 15:173-178, 1984.

Conlon BJ, McSwain SD, Smith DW. Topical gentamicin and ethacrynic acid: effects on cochlear function. Laryngoscope 108:1087-1089, 1998.

CotANCHE DA. Structural recovery from sound and aminoglycoside damage in the avian cochlea. Audiol. Neurootol. 4:271-285, 1999.

DeCicco MJ, Hoffer ME, Kopke RD, Wester D, Allen KA, GottSHALL K, O'LEARY MJ. Round-window microcatheter-administered microdose gentamicin: results from treatment of tinnitus associated with Meniere's disease. Int. Tinnitus J. 4:141-143, 1998.

DeGroot JCMJ, Meeuwsen F, Ruizentaal We, Veldman Je. Ultrastructural localization of gentamicin. Hear. Res. 50:35-42, 1990.

Dulon D, Aran JM, Zajic G, Schacht J. Comparative uptake of gentamicin, netilmicin, and amikacin in the guinea pig cochlea and vestibule. Antimicrob. Agents Chemother. 30:96-100, 1986.

Dulon D, Hiel H, Aurousseau C, Erre JP, Aran JM. Pharmacokinetics of gentamicin in the sensory hair cells of the organ of Corti: rapid uptake and long term persistence. C. R. Acad. Sci. III. 316:682-687, 1993.

FedersPIL P. Pharmacokinetics of aminoglycoside antibiotics in the perilymph. In: Lerner SA, Mats GJ, Hawkins Jr. JE (eds) Aminoglycoside Ototoxicity. Boston, Little Brown, 1981, pp 99-108

Forge A, Schacht J. Aminoglycoside antibiotics. Audiol. Neurootol. 5:3-22, 2000.

GAO WQ. Therapeutic potential of neurotrophins for treatment of hearing loss. Mol. Neurobiol. 17:17-31, 1998.

Hashino E, Shero M. Endocytosis of aminoglycoside antibiotics in sensory hair cells. Brain Res. 704:135-140, 1995.
Hashino E, Shero M, SAlvi RJ. Lysosomal targeting and accumulation of aminoglycoside antibiotics in sensory hair cells. Brain Res. 777:75-85, 1997.

HAwkINS JR JE. Comparative otopathology: aging, noise, and ototoxic drugs. Adv. Otorhinolaryngol. 20:125-141, 1973.

Hawkins JR JE, Johnsson LG. Histopathology of cochlear and vestibular ototoxicity. In: Lerner SA, Mats GJ, Hawkins Jr JE (eds) Aminoglycoside ototoxicity Little Brown, Boston, 1981, pp 175195

Hayashida T, Nomura Y, Iwamori M, Nagai Y, Kurata T. Distribution of gentamicin by immunofluorescence in the guinea pig inner ear. Arch. Otorhinolaryngol. 242:257-264, 1985.

HaYASHIdA T. An immunohistochemical method for the study of aminoglycoside ototoxicity in the guinea pig cochlea using decalcified frozen sections. Arch. Otorhinolaryngol. 246:161-164, 1989.

Hayashida T, Hiel H, Dulon D, Erre JP, Guihaume A, Aran JM. Dynamic changes following combined treatment with gentamicin and ethacrynic acid with and without acoustic stimulation. Acta Otolaryngol. (Stockh.) 108:404-413, 1989.

Hiel H, Bennani H, Erre J, Aurousseau C, Aran J. Kinetics of gentamicin in cochlear hair cells after chronic treatment. Acta Otolaryngol. (Stockh.) 112:272-277, 1992a.

Hiel H, Schamel A, Erre J, Hayashida T, Dulon D, Aran J. Cellular and subcellular localization of tritiated gentamicin in the guinea pig cochlea following combined treatment with ethacrynic acid. Hear. Res. 57:157-165, 1992b.

Hiel H, Erre J, Aurousseau C, Bouali R, Dulon D, Aran J. Gentamicin uptake by cochlear hair cells precedes hearing impairment during chronic treatment. Audiology 32:78-87, 1993.

Husmann KR, Morgan AS, Girod DA, Durham D. Round window administration of gentamicin: a new method for the study of ototoxicity of cochlear hair cells. Hear. Res. 125:109-119, 1998.

IChimiya I, Adams JC, Kimura R. Changes in immunostaining of cochleas with experimentally induced endolymphatic hydrops. Ann. Otol. Rhinol. Laryngol. 103:457-468, 1994.

IMAMURA S, ADAMS JC. Immunolocalization of peptide 19 and other calcium-binding proteins in the guinea pig cochlea. Anat. Embryol. (Berl.) 194:407-418, 1996.

Iwamori M, Tayama N, Nomura Y, Nagai Y. Hormone-dependent enhancement in binding of oto- and nephrotoxic aminoglycoside antibiotics. Acta Otolaryngol. Suppl. (Stockh.) 514:117121, 1994.

Kikuchi T, Kimura RS, AdAms JC. Gap junctions in the rat cochlea: immunohistochemical and ultrastructural analysis. Anat. Embryol. (Berl.) 191:101-118, 1995.

Kimura RS, Lee K-S, Nye CL, Trehey JA. Effects of systemic and lateral semicircular canal administration of aminoglycosides on normal and hydropic inner ears. Acta Otolaryngol. (Stockh.) 111:1021-1030, 1991.

LEAKE PA, SNYDER RL. Uptake of horseradish peroxidase from perilymph by cochlear hair cells. Hear. Res. 25:153-171, 1987.

Marzella PL, Clark GM. Growth factors, auditory neurones and cochlear implants: a review. Acta Otolaryngol. 119:407-412, 1999.

Meyer J, Mack AL, Gummer AW. Pronounced infracuticular endocytosis in mammalian outer hair cells. Hear. Res. 161:10-22, 2001.

Mugnaini E, Dahl AL. Zinc-aldehyde fixation for light-microscopic immunocytochemistry of nervous tissues. J. Histochem. Cytochem. 31:1435-1438, 1983.

Nadol JB, Adams JC, Kim JR. Degenerative changes in the organ of Corti and lateral cochlear wall in experimental endolymphatic hydrops and human Meniere's disease. Acta Otolaryngol. Suppl. (Stockh.) 519:47-59, 1995. 
Nakashima T, Teranishi M, Hibi T, Kobayashi M, Umemura M. Vestibular and cochlear toxicity of aminoglycosides-a review. Acta Otolaryngol. 120:904-911, 2000.

Portmann M, Darrouzet J, Coste C. Distribution within the cochlea of dihydrostreptomycin injected into the circulation. Arch. Otolaryngol. (Chicago). 100:473-475, 1974.

Richardson GP, Forge A, Cros CJ, Fleming J, Brown SD, Steel KP. Myosin VIIA is required for aminoglycoside accumulation in cochlear hair cells. J. Neurosci. 17:9506-9519, 1997.

RyBACK LP. Ototoxic mechanisms. In: Altschuler RA, Bobbin RP, Hoffman DW (eds) Neurobiology of hearing: the cochlea. Raven Press, New York, 1986, pp 442-454

Sснаснт J. Molecular mechanisms of drug-induced hearing loss. Hear. Res. 22:297-304, 1986.

SCHACHT J. Biochemical basis of aminoglycoside ototoxicity. Otolaryngol. Clin. N. Am. 26:845-856, 1993.

Schulte BA, Adams JC. Distribution of immunoreactive $\mathrm{Na}^{+}, \mathrm{K}^{+}$ATPase in gerbil cochlea. J. Histochem Cytochem. 37:127-134, 1989.

Siegel JH, BRownell WE. Synaptic and golgi membrane recycling in cochlear hair cells. J. Neurocytol. 15:311-328, 1986.

Spicer SS, Schulte BA. Golgi-canalicular reticulum system in ion transporting fibrocytes and outer sulcus epithelium of gerbil cochlea. Anat. Rec. 249:117-127, 1997.

Spicer SS, Thomopoulos GN, Schulte BA. Cytologic evidence for mechanisms of $\mathrm{K}+$ transport and genesis of Hensen bodies and subsurface cisternae in outer hair cells. Anat. Rec. 251:97-113, 1998.

Stone JS, Rubel EW. Cellular studies of auditory hair cell regeneration in birds. Proc. Natl. Acad. Sci. U S A 97:11714-11721, 2000.

Tachibana M, Morioka H, Machino M, Mizukoshi O. Binding sites of an aminoglycoside in the cochlea examined by immunocytochemistry. Histochemistry 83:237-240, 1985.

Takada A, Bledsoe JR S, Schacht J. An energy-dependent step in aminoglycoside ototoxicity: prevention of gentamicin ototoxi- city during reduced endolymphatic potential. Hear. Res. 19:245-251, 1985.

Tran Ba Huy P, Manuel C, Meulemans A. Kinetics of aminoglycoside antibiotics in perilymph and endolymph in animals. In: Lerner SA, Mats GJ, Hawkins Jr JE (eds) Aminoglycoside ototoxicity. Little, Brown, Boston, 1981a, pp $81-97$

Tran Ba Huy P, Manuel C, Meulemans A, Sterkers O, Amiel C. Pharmacokinetics of gentamicin in perilymph and endolymph of the rat as determined by radioimmunoassay. J. Infect. Dis. 143:476-486, 1981b.

Tran Ba Huy P, Meulemans A, Wassef M, Manuel C, Sterkers O, Amiel C. Gentamicin persistent in rat endolymph and perilymph after two-day constant infusion. Antimicrob. Agents Chemther. 23:344-346, 1983.

Tran Ba Huy P, Bernard P, Schacht J. Kinetics of gentamicin uptake and release in the rat; comparison of inner ear tissues and fluids with others organs. J. Clin. Invest. 77:1492-1500, 1986.

Veldman JE, Meeuwsen F, van Dijk M, Key Q, Huizing EH. Progress in temporal bone histopathology. II. Immuno-technology applied to the temporal bone. Acta Otolaryngol. Suppl. 423:29-35, 1985.

von Ilberg C, Spoendin H, Arnold W. Autoradiographical distribution of locally applied dihydrostreptomycin in the inner ear. Acta Otolaryngol. (Stockh.) 71:159-165, 1971.

Wersall J, LundQuist PG, BJorkRoth B. Ototoxicity of gentamicin. J. Infect. Dis. 119:410-416, 1969.

Wersall J. Ototoxic antibiotics: a review. Acta Otolaryngol. Suppl. 519:26-29, 1995.

Williams SE, Zenner HP, Schacht J. Three molecular steps aminoglycoside ototoxicity demonstrated in outer hair cells. Hear. Res. 30:11-18, 1987.

Yamane H, NAKaI Y, Konishi K. Furosemide-induced alteration of drug pathway to cochlea. Acta Otolaryngol. Suppl. 447:28-35, 1988. 